\title{
LILIA TIMERMAN
}

\section{Avaliação clínica e microbiológica periodontal em portadoras de cardiopatia valvar na gestação}

Tese apresentada à Faculdade de Medicina da Universidade de São Paulo para obtenção do título de Doutor em Ciências

Área de concentração: Cardiologia

Orientadora: Profa. Dra. Walkiria Samuel Avila

São Paulo

2008 


\section{DEDICATÓRIA}


Ao meu marido Sergio amigo, amante e companheiro, por vencermos mais esta etapa juntos.

Aos meus filhos Thiago, Felipe e Bruno, razões de minha vida.

Aos meus pais José e Eleonora, e aos meus irmãos Anete e Gilberto, pelo carinho que nos une. 
AGRADECIMENTOS 
À minha orientadora, Profa. Dra. Walkíria Samuel Ávila, pela amizade, sabedoria, apoio, paciência e estímulo em todas as fases deste trabalho, minha admiração eterna.

Ao Prof. Dr. Sergio Timerman, visionário de importância ímpar no âmbito das emergências no Brasil, a quem devo o despertar de meu interesse pela pesquisa.

Ao Prof. Dr. Leopoldo Soares Piegas, Diretor do Instituto Dante Pazzanese de Cardiologia, pela confiança e cooperação.

Às cirurgiãs-dentistas da Seção de Odontologia do Instituto Dante Pazzanese de Cardiologia, Dras. Valéria Cristina Leão de Sousa Conrado, Ana Carolina Porrio de Andrade e Gabriella Avezum Mariano da Costa de Angelis pela amizade, solidariedade e compreensão nos momentos em que estive ausente.

À secretária, advogada e "irmã" Rose Oliveira da Costa, da Seção de Odontologia do Instituto Dante Pazzanese de Cardiologia, a quem muito admiro pelo entusiasmo, estímulo e colaboração. Obrigada por tudo.

A Roberta de Sousa, do Laboratório de Epidemiologia e Estatística do Instituto Dante Pazzanese de Cardiologia, pela orientação estatística neste trabalho. 
Ao Prof. Dr. Noedir Antonio Groppo Stolf, Presidente do Conselho Diretor do Instituto do Coração, pela oportunidade oferecida para desenvolver este estudo.

Ao Prof. Dr. Ricardo Simões Neves, Diretor da Unidade de Odontologia, e às funcionárias da Unidade de Odontologia do Instituto do Coração, que me acolheram como uma filha e possibilitaram a conclusão deste trabalho.

À Profa. Dra. Itamara Lucia Itagiba Neves, da Unidade de Odontologia do Instituto do Coração, pela amizade e incessante ajuda, minha admiração e meu muito obrigado.

À Dra. Ana Maria Milani Gouveia e à voluntária Sra. Maria Inês R. de Oliveira Campos, do Setor de Cardiopatia e Gravidez e Planejamento Familiar da Unidade de Cardiopatias Valvares do Instituto do Coração, pelo inestimável apoio na seleção das pacientes incluídas nesta dissertação.

À Comissão de Pós Graduação, em especial as Sras. Eva M. G. de Oliveira, Juliana Lattati Sobrinho e Neuza Rodrigues Dini, pela constante e incansável colaboração.

Ao Prof. Dr. Giuseppe Alexandre Romito, da Disciplina de Periodontia do Departamento de Estomatologia da F.O.U.S.P., pela amizade, paciência e coorientação em todas as fases deste estudo, minha admiração e meu muito obrigado. 
Ao Dr. Cláudio M. Panutti, da Disciplina de Periodontia do Departamento de Estomatologia da F.O.U.S.P., pelas valiosas contribuições e sugestões para a publicação deste trabalho.

À Dra. Silvia Linard Marcelino, pós-graduanda da Disciplina de Periodontia do Departamento de Estomatologia da F.O.U.S.P., pela dedicação e imprescindível participação na fase microbiológica deste estudo.

Ao Prof. Ass. Fábio Daumas Nunes, Chefe do Laboratório de Microbiologia Molecular da F.O.U.S.P., pela confiança em mim depositada para execução deste trabalho.

À Profa. Dra. Ana Cristina D’Andreta Tanaka e aos profissionais do Centro de Saúde Geraldo de Paula Souza, da Faculdade de Saúde Pública da Universidade de São Paulo, meu agradecimento pela disposição para a captação de pacientes.

A todas as pacientes que, ao concordar espontaneamente em participar desta pesquisa tornando-a factível, minha incessante gratidão.

À Fundação de Amparo à Pesquisa do Estado de São Paulo (FAPESP), que tornou viável a realização deste estudo através da concessão do Auxílio à Pesquisa, processo 06/57931-2. 
EPÍGRAFE 
"Não se deixe levar pela distância entre seus sonhos e a realidade: se você é capaz de sonhá-los, também pode realizá-los”.

Belva Davis 
NORMALIZAÇÃO ADOTADA 
Esta tese está de acordo com as seguintes normas, em vigor no momento desta publicação:

Referências: adaptado de International Commitee of Medical Journals Editors (Vancouver)

Universidade de São Paulo. Faculdade de Medicina. Serviço de Biblioteca e Documentação. Guia de apresentação de dissertações, teses e monografias. Elaborado por Annelise Carneiro da Cunha, Maria Julia de A. L. Freddi, Maria F. Crestana, Marinalva de Souza Aragão, Suely Campos Cardoso, Valéria Vilhena. $2^{\mathrm{a}}$ Ed. São Paulo: Serviço de Biblioteca e Documentação; 2005

Abreviaturas dos títulos dos periódicos de acordo com List of Journals Indexed in Index Medicus. 


\section{SUMÁRIO}




\section{SUMÁRIO}

Listas de abreviaturas, siglas e símbolos

\section{Resumo}

\section{Summary}

1 INTRODUÇÃO

2 OBJETIVOS

3 MÉTODOS

3.1 Casuística

3.1.1.Critérios de inclusão 10

3.1.2. Critérios de não-inclusão 11

3.2 Calibração da Examinadora 12

\begin{tabular}{ll}
\hline 3.3 Etapas do estudo & 12 \\
\hline 3.3 .1 Entrevista incial
\end{tabular}

$\begin{array}{ll}\text { 3.3.1 Entrevista inicial } & 12 \\ 3.3 .2 \text { Exame Clinico } & 13\end{array}$

\begin{tabular}{ll}
\hline 3.3 .2 Exame Clínico & 13 \\
\hline 3.3 .3 Coleta das amostras
\end{tabular}

\begin{tabular}{ll}
\hline 3.3 .3 Coleta das amostras & 14 \\
\hline
\end{tabular}

3.4 Processamento laboratorial das amostras 15

\begin{tabular}{ll}
3.4 .1 Extração do DNA & 15 \\
\hline 3.4. Quantificação do
\end{tabular}

\begin{tabular}{ll}
\hline 3.4. Quantificação do DNA & 15
\end{tabular}

\begin{tabular}{ll}
\hline 3.4 .3 Detecção bacteriana por PCR & 16 \\
\hline Análise
\end{tabular}

3.5 Análise estatística 18

4 RESULTADOS $\quad 19$

4.1 Análise da casuística $\quad 20$

\begin{tabular}{ll}
\hline 4.2 Resultados Clínicos & 26
\end{tabular}

\begin{tabular}{ll}
\hline 4.3 Resultados Microbiológicos & 30 \\
\hline
\end{tabular}

5 DISCUSSÃO 33

5.1 Considerações finais $\quad 39$

\begin{tabular}{ll}
\hline 5.2 Limitações do estudo & 39 \\
\hline
\end{tabular}

6 CONCLUSÕES $\quad 40$

7 ANEXOS $\quad 42$

8 REFERÊNCIAS $\quad 46$

Apêndice 
LISTA DE ABREVIATURAS,
SIGLAS E SÍMBOLOS 


\section{LISTA DE ABREVIATURAS}

c.c. coeficiente de correlação

et. al. e outros

ex. exemplo

fig. figura

P. gingivalis Porphyromonas gingivalis 


\section{LISTA DE SIGLAS}

\begin{tabular}{|c|c|}
\hline AHA & American Heart Association \\
\hline Ao & aórtica \\
\hline ATCC & American Type Culture Collection \\
\hline CAPPesq & $\begin{array}{l}\text { Comissão de Ética para Análise de Projetos de } \\
\text { Pesquisa }\end{array}$ \\
\hline $\mathrm{CF}$ & classe funcional \\
\hline CSGPS & Centro de Saúde Geraldo de Paula Souza \\
\hline dATP & desoxiadenosina trifosfato \\
\hline dCTP & desoxicitidina trifosfato \\
\hline dGTP & desoxiguanosina trifosfato \\
\hline DM & diabetes mellitus \\
\hline DNA & Ácido Desoxirribonucleico \\
\hline dNTP & $\begin{array}{l}\text { solução de 2'- desoxirribonucleico 5'- trifosfato: } \\
\text { dATP, dTTP, dCTP e dGTP/ desoxirribonucleico } \\
\text { trifosfato }\end{array}$ \\
\hline$d p$ & desvio padrão \\
\hline DP & doença periodontal \\
\hline dTTP & desoxitimidina trifosfato \\
\hline El & Endocardite Infecciosa \\
\hline F.O.U.S.P. & $\begin{array}{l}\text { Faculdade de Odontologia da Universidade de São } \\
\text { Paulo }\end{array}$ \\
\hline GC & Gestantes Cardiopatas \\
\hline GNC & Gestantes não - Cardiopatas \\
\hline
\end{tabular}




\begin{tabular}{|c|c|}
\hline HC FMUSP & $\begin{array}{l}\text { Hospital das Clínicas da Faculdade de Medicina da } \\
\text { Universidade de São Paulo }\end{array}$ \\
\hline ICC & correlação de intraclasse \\
\hline IDPC & Instituto Dante Pazzanese de Cardiologia \\
\hline IG & idade gestacional \\
\hline InCor & Instituto do Coração \\
\hline IP & índice de placa \\
\hline IS & índice de sangramento \\
\hline LEC/ MG & linha esmalte-cemento à margem gengival \\
\hline Mi & mitral \\
\hline $\mathrm{n}$ & número \\
\hline NBP & nascimento com baixo peso \\
\hline $\mathrm{NCl}$ & nível clínico de inserção \\
\hline NYHA & New York Heart Association \\
\hline OR & odds ratio \\
\hline $\mathrm{pb}$ & pares de base \\
\hline PCR & reação de polimerase em cadeia \\
\hline PCS & profundidade clínica de sondagem \\
\hline $\mathrm{pH}$ & potência do Hidrogênio \\
\hline TAE & Tris- acetato \\
\hline
\end{tabular}




\section{LISTA DE SÍMBOLOS}

\begin{tabular}{|c|c|}
\hline $\mathrm{cm}$ & centímetro \\
\hline $\mathrm{F}$ & teste Exato de Fischer \\
\hline g & grama \\
\hline Icor & Índice de correlação \\
\hline $\mathrm{kg}$ & kilograma \\
\hline $\mathrm{m}$ & metro \\
\hline M & molar \\
\hline $\mathrm{Mg}$ & magnésio \\
\hline $\mathrm{MgCl} 2$ & cloreto de magnésio \\
\hline $\mathrm{ml}$ & mililitros \\
\hline$\mu l$ & microlitro \\
\hline $\mathrm{mm}$ & milímetro \\
\hline $\mathrm{mM}$ & milimolar \\
\hline $\mathrm{mm} / \mathrm{s}$ & milímetro por segundo \\
\hline $\mathrm{mmHg}$ & milímetros de mercúrio \\
\hline $\mathrm{mV}$ & milivolt \\
\hline $\mathrm{nm}$ & nanômetro \\
\hline$n$ & número \\
\hline$\%$ & percentagem \\
\hline$p$ & valor de $p$ \\
\hline
\end{tabular}


$\mathrm{p}$ teste QuiQuadrado de Pearson

S segundo

U unidade

V

volts 
Microorganismos da cavidade oral têm sido admitidos como causadores de doenças sistêmicas com reconhecido mecanismo de disseminação via corrente sangüínea. Diferentes fatores, incluindo a presença da doença periodontal, têm influência no risco de bacteremia oral, podendo ocasionar endocardite infecciosa por Streptococcus viridans. Sendo assim, a manutenção da saúde bucal adquire elevado grau de importância em gestantes portadoras de doença valvar reumática, em que o risco de endocardite infecciosa é eminente. A escassez científica fez deste tema o objetivo deste estudo: investigar a condição clínica periodontal de gestantes portadoras de cardiopatia valvar, identificando agentes periodontopatógenos nas amostras coletadas de saliva, sulco/bolsa periodontal, Para tanto, foram estudadas 52 gestantes cardiopatas (GC) e 70 gestantes não-cardiopatas (GNC). A condição periodontal foi avaliada empregando-se profundidade clínica de sondagem (PCS), nível clínico de inserção ( $\mathrm{NCl}$ ), linha esmaltecemento/margem gengival (LEC/MG), índice de sangramento (IS) e índice de placa bacteriana (IP). As seguintes médias foram obtidas para os parâmetros periodontais avaliados: PCS: 1.52 (GC) e 1.45 (GNC); NCl: 1.13 (GC) e 1.02 (GNC); LEC/MG: 0.41 (GC) e 0.40 (GNC); IS: 7.34 (GC) e 6.27 (GNC) e IP: 12.19 (GC) e 13.48 (GNC). Não houve diferença entre os grupos para $\circ \mathrm{NCl}(p=0,612)$. A presença da Porphyromonas gingivalis na saliva foi maior $(p=0,007)$ no $G N C$, porém não houve diferença nas amostras de sulco/bolsa periodontal. 
Descritores: 1.Doenças periodontais 2.Cardiopatia reumática 3.Gestantes 4.Endocardite 5.Febre reumática 6.Porphyromonas gingivalis 7.Gravidez 8.Higiene bucal 
Microorganisms of the oral cavity are known to cause systemic diseases, spread through sanguine current. Different factors, including the presence of periodontal disease, influencing the risk of oral bacteremia could cause infectious endocarditis for Streptococcus viridans. Nevertheless, the maintenance of the oral health is extremely important in pregnant women with rheumatic valvar disease, in which the risk of infectious endocarditis is eminent. The aim of this study was to investigate the clinical periodontal condition of pregnant women with valvar disease and to identify the presence of Porphyromonas gingivalis in saliva and subgingival samples. For these purposes, we studied 52 pregnant with valvar disease (GC) and 70 healthy pregnant women $(\mathrm{GNC})$. The following periodontal parameters were evaluated: probing depth (PCS), clinical attachment level ( $\mathrm{NCl}$ ), gingival margin location (LEC/MG), bleeding on probing (IS) and plaque index (IP). The following mean periodontal parameters were obtained: PCS: 1.52 (GC) e 1.45 (GNC); NCl: 1.13 (GC) e 1.02 (GNC); LEC/MG: 0.41 (GC) e 0.40 (GNC); IS: 7.34 (GC) e 6.27 (GNC) e IP: 12.19 (GC) e 13.48 (GNC). There was no statistical difference for $\mathrm{NCl}$ among the groups. There was no difference between periodontal clinical conditions in pregnant women with valvar disease and healthy pregnant women. The presence of the Porphyromonas gingivalis in saliva samples of healthy pregnant women is statistically higher than in pregnant woman with valvar disease; however, there was no difference in periodontal samples. 
Descriptors: 1.Periodontal diseases 2.Rheumatic heart disease 3.Pregnat women 4.Endocarditis 5.Rheumatic fever 6.Porphyromonas gingivalis 7.Pregnancy 8.Oral hygiene 
1 INTRODUÇÃO 
A doença periodontal (DP) é uma infecção crônica associada a microorganismos aeróbios e anaeróbios que resultam em aprofundamento patológico do sulco gengival pela migração apical do epitélio juncional, destruição do ligamento periodontal e do osso alveolar ${ }^{1,2}$.

Estima-se que nos EUA a DP acometa $35 \%$ da população adulta. Destes, $22 \%$ apresentam a forma moderada, enquanto que $13 \%$ da população acima de 30 anos apresentam-na de moderada a grave $e^{3,4}$.

No Brasil, Abbeg ${ }^{5,6}$ mostrou uma relação positiva entre os fatores sócioeconômicos, níveis de biofilme bacteriano e gengivite em adultos e verificou que $74,3 \%$ da população examinada apresentavam sangramento gengival e que $83,2 \%$ desta pertenciam à faixa etária entre 30 e 34 anos. De acordo com estudos de Yalcin ${ }^{7}$, em 2002, quase metade da população $(45,9 \%)$ era compreendida entre 25 e 35 anos e a grande maioria (70,5\%) não havia recebido tratamento periodontal prévio. A prevalência da DP é universal, destacando-se como um dos principais problemas de saúde pública na área odontológica nos países pobres ${ }^{8}$.

Page $^{9}$, em 1998, já apontava um novo paradigma da patogênese da DP, ressaltando sua característica multifatorial com influência no aparecimento, na manifestação e na evolução clínica da doença e na sua resposta ao tratamento. 
Os fatores de risco associados à DP referem-se às condições de saúde, ao comportamento e estilo de vida, e ao meio ambiente que cerca a população envolvida ${ }^{10}$.

A DP destrutiva é conseqüência de interação da genética, do meio ambiente, do hospedeiro, da especificidade e patogenicidade da microbiota envolvida $^{11,12}$. A presença dos microorganismos é fundamental para o início da DP, contudo, a manifestação e a evolução da doença estão relacionadas a fatores próprios do paciente, com maior relevância para: idade, sexo, tabagismo, resposta inflamatória do hospedeiro, características do tecido conjuntivo e do osso alveolar ${ }^{13}$, e das co-morbidades associadas ${ }^{3,10}$. Entre os fatores relacionados ao estilo de vida destaca-se o tabagismo, mais amplamente estudado ${ }^{14-16} \mathrm{e}$, dentre as co-morbidades, o diabetes mellitus ${ }^{17,}$ 18, desordem metabólica em que a DP é reconhecida como a sexta complicação.

Quanto a idade e ao sexo, na mulher jovem destaca-se a gengivite gravídica, podendo ocorrer em 30 a 100\% das mulheres grávidas ${ }^{19}$, quando os sinais inflamatórios, tais como edema, eritema e sangramento espontâneo, predominam. A gengivite crônica durante a gravidez pode ser localizada ou generalizada e tem sido atribuída às modificações hormonais que podem resultar em aumento do processo inflamatório e, conseqüentemente, em crescimento gengival ${ }^{7}$.

As dificuldades no reconhecimento da especificidade dos agentes microbianos da DP fundamentam-se no expressivo número de espécies, observando-se que cerca de 300 a 400 são encontradas no biofilme 
bacteriano. Deste espectro, possivelmente 10 a 20 espécies participem da patogenicidade e da destruição, na $\mathrm{DP}^{12}$.

Os microorganismos envolvidos na DP são, na maioria, bacilos anaeróbios Gram-negativos com alguns coccus anaeróbios e grande quantidade de espiroquetas. Certas espécies de bactérias como Porphyromonas gingivalis (P.gingivalis), Prevotella intermédia, Bacteróides forsythus, Aggregobacter actinomycetemcomitans, Treponema denticola, entre outras, têm sido encontradas em sulco/bolsa periodontal ${ }^{20,21}$. Dentre as bactérias estudadas, Aggregobacter actinomycetemcomitan, Porphyromonas gingivalis e Tannerella forsythia têm mostrado maior relevância etiológica no início e progressão das lesões periodontais destrutivas $^{22-25}$.

Nesse sentido, reconhecidamente mais precária ${ }^{26,27}$, a condição periodontal durante a gravidez tem forte implicação no aparecimento de infecções sistêmicas, em particular a ocorrência da endocardite infecciosa $(E \mathrm{I})^{28-30}$ em pacientes suscetíveis, como as portadoras de doença valvar reumática ${ }^{31}$.

A El é a infecção do endotélio do coração caracterizada por vegetações microbianas encontradas nas valvas cardíacas, com incidência estimada em 3,8 casos por 100.000 pessoas/ano ${ }^{32}$.

A gravidez não modifica a incidência da El, estimada entre 500 a 800 partos $^{33}$, porém as modificações fisiológicas da cavidade bucal e a negligência da higiene oral favorecem a ocorrência da DP e a exposição ao risco de El na mulher portadora de doença valvar reumática. Esta, que 
corresponde a $50 \%$ das cardiopatias na gravidez, está associada à alta freqüência de complicações, entre elas a El, ainda considerada a principal causa não-obstétrica de morte materna no ciclo gravídico-puerperal ${ }^{34-36}$.

Alguns estudos demonstram que a cavidade bucal é a principal porta de entrada para agentes etiológicos da El, considerada uma infecção grave porque, apesar dos avanços em seu diagnóstico e tratamento, ainda está associada a altas taxas de morbidade e mortalidade ${ }^{32,33}$.

Isto exposto, verifica-se que na literatura não existem dados sobre a condição periodontal em mulheres grávidas portadoras de doença valvar reumática. Logo, o acompanhamento destas mulheres demanda atenção de uma equipe multidisciplinar, visando à eliminação dos fatores agravantes na assistência pré-natal. Neste contexto, deve-se incluir a participação efetiva do cirurgião-dentista no diagnóstico, na prevenção e no tratamento das doenças bucais, pois, pelas características de etiopatogenicidade, as doenças periodontais desempenham papel significativo dentre os fatores que podem atuar no âmbito da gravidez de alto risco. 
2 OBJETIVOS 
OBJETIVO GERAL: Estudar a condição clínica e microbiológica periodontal de gestantes portadoras de doença valvar reumática.

OBJETIVOS ESPECÍFICOS: Comparar mulheres portadoras e nãoportadoras de doença valvar reumática durante a gravidez, quanto a:

1) Condição clínica periodontal;

2) Identificação de agentes periodontopatógenos nas amostras coletadas de saliva, sulco/bolsa periodontal. 
3 MÉTODOS 


\section{MÉTODOS}

O estudo foi realizado no Setor de Cardiopatia e Gravidez e Planejamento Familiar da Unidade de Cardiopatias Valvares e na Unidade de Odontologia do Instituto do Coração do Hospital das Clínicas da Faculdade de Medicina da Universidade de São Paulo - InCor / HCFMUSP em conjunto com o Setor de Cardiopatia e Gravidez e Planejamento Familiar do Instituto Dante Pazzanese de Cardiologia (IDPC), o Centro de Saúde Geraldo de Paula Souza (CSGPS) da Faculdade de Saúde Pública, e a Disciplina de Periodontia do Departamento de Estomatologia da Faculdade de Odontologia da Universidade de São Paulo (F.O.U.S.P.).

O estudo foi aprovado pela Comissão de Ética para análise de Projetos de Pesquisa (CAPPesq) do HC FMUSP (Apêndice), processo 199/05, em 24 de novembro de 2005, após aprovação do Comitê de Ética em Pesquisa do Instituto do Coração (InCor) (Apêndice), processo 2557-04/177, em 04 de novembro de 2005, e do Comitê de Ética em Pesquisa do IDPC (Apêndice), protocolo $n^{\circ} .3408$, em 14 de Março de 2006 e iniciado após obtenção da assinatura do Termo de Consentimento Livre e Esclarecido das participantes (Apêndice), de acordo com as normas da Resolução $n^{\circ}$. 196, de 10 de outubro de 1996, do Conselho Nacional de Saúde. A pesquisa teve apoio financeiro da Fundação de Amparo à Pesquisa do Estado de São Paulo 
(FAPESP) processo 57931-2 (Apêndice), aprovada em 12 de Janeiro de 2007.

\subsection{CASUÍSTICA}

No período de dezembro de 2005 a novembro de 2007 foram selecionadas 122 gestantes e divididas em dois grupos:

- GC - Gestantes portadoras de doença valvar reumática em número (n) de 70

- GNC - Gestantes não-portadoras de doença valvar reumática, $\mathrm{n}=52$.

Todas faziam seguimento obstétrico pré-natal e portavam documento com informações sobre a assistência pré-natal obstétrica como: idade gestacional, antecedentes obstétricos e dados antropométricos maternofetais.

Foram mantidas as medicações de indicação cardiológica e a penicilina G benzatina no GC, de acordo com as recomendações da Sociedade de Cardiologia do Estado de São Paulo ${ }^{37}$ e da American Heart Association ${ }^{38}$. 


\subsubsection{Critérios de inclusão}

a) Clínicos Mulheres com idade entre 18 e 35 anos, portadoras de doença valvar reumática definida por história clínica e exame físico e documentada pelo ecodopplercardiograma, submetidas ou não à intervenção cirúrgica ou percutânea antes da gravidez, e em classe funcional (CF) I/II, de acordo com a classificação da New York Heart Association (NYHA) ${ }^{39-41}$ : grupo GC.

b) Obstétricos Gravidez de feto único e idade gestacional (IG) entre a $13^{\mathrm{a}} \mathrm{e}$ a $40^{a}$ semana: grupos GC e GNC.

c) Odontológicos Ambos os grupos, com preservação de não menos que 20 dentes naturais.

Empregou-se o critério de Tonetti e Claffey $^{42}$ para o diagnóstico da doença periodontal. Para periodontite crônica utilizou-se a presença de perda de inserção proximal $\geq 5 \mathrm{~mm}$ em $\geq 30 \%$ dos dentes presentes.

\subsubsection{Critérios de não-inclusão}

a) Clínicos Portadoras de outras lesões cardíacas, diabetes mellitus, lesões de outros órgãos e doenças infecciosas;

b) Obstétricos Complicações que exigiam cuidados obstétricos especiais;

c) Odontológicos Uso de antibiótico ou tratamento periodontal realizado num período menor que três meses antes da data do exame clínico, exceção 
feita à penicilina $G$ benzatina, prescrita para profilaxia da doença reumática no grupo GC.

d) Sociais Hábito de ingerir bebidas alcoólicas, de fumar e/ou de usar drogas ilícitas; 


\subsection{Calibração da Examinadora}

A investigação foi realizada por uma única examinadora. Previamente ao início da coleta de dados clínicos a examinadora foi submetida a um processo de calibração, foram atendidos dez pacientes e avaliados, para os parâmetros clínicos periodontais, cinco dentes de cada paciente em dois dias alternados, todos atendidos na disciplina de Periodontia da F.O.U.S.P.

O procedimento adotado foi concordância intra-examinador ${ }^{43}$. coeficiente de correlação de intraclasse (ICC), em nível local, variou entre 0,83 e 0,89 para PS e 0,82 e 0,90 para $\mathrm{NCl}$; no âmbito de $\mathrm{PS}$, variou entre 0,92 e 0,97 , e, de $\mathrm{NCl}$, entre 0,88 e 0,95 .

\subsection{Etapas do estudo}

\subsubsection{Entrevista inicial}

A realização das entrevistas de cada gestante foi de responsabilidade da própria examinadora.

A entrevista inicial, realizada em consultório odontológico, constou de perguntas feitas verbalmente com base em questionário previamente estabelecido (Anexo A). Após o término do preenchimento, a examinadora 
consultou o prontuário hospitalar com o objetivo de ter informações completas.

\subsubsection{Exame Clínico}

Foi utilizado espelho clínico e uma sonda milimetrada Hu FriedyPCPUNC-15, para exame de sulcos/bolsas, sendo registrados os maiores valores de sondagem obtidos em cada uma das seguintes regiões: distovestibular, centro-vestibular, mésio-vestibular, disto-lingual, centro-lingual e mésio-lingual, de todos os dentes presentes, excluindo os terceiros molares.

Os seguintes parâmetros clínicos foram registrados (Anexo B):

1. Profundidade Clínica de Sondagem (PCS): distância (em mm) compreendida entre a margem gengival e o fundo do sulco gengival ou da bolsa periodontal;

2. Distância da linha esmalte-cemento à margem gengival (LEC/MG): espaço que vai da linha esmalte-cemento à margem gengival;

2. Nível Clínico de Inserção (NCl): correspondente à diferença aritmética dos valores de PCS e LEC/MG;

3. Índice de Sangramento (IS) realizada nas quatro faces de cada dente avaliado $^{44}$

4. Índice de Placa bacteriana(IP) ${ }^{45}$.

Todas as gestantes que tiveram a DP diagnosticada foram encaminhadas para tratamento periodontal não-cirúrgico. 


\subsubsection{Coleta das amostras}

A metodologia para coleta das amostras para análise microbiológica foi utilizada por Romito et al. ${ }^{46}$ a qual, resumidamente, consiste em selecionar os quatro sítios que apresentaram a maior profundidade clínica de sondagem de cada quadrante. Quando não foi possível obedecer a esta condição, as amostras foram coletadas respeitando-se a melhor distribuição dentro dos dentes presentes nos quadrantes.

Para a coleta microbiológica os dentes foram previamente isolados com roletes de algodão e as amostras subgengivais obtidas introduzindo-se pontas de papel absorvente Tanari, $\mathrm{n}^{\circ}$. 40, estéreis, no interior do sulco gengival ou da bolsa periodontal. As pontas foram mantidas no local por cerca de $20 \mathrm{~s}^{47} \mathrm{e}$, após sua remoção, armazenadas em frascos estéreis. Para a coleta salivar, solicitou-se às pacientes que mastigassem parafina (Parafilm "M" - Laboratory Film - American National Can - Chicago, IL. 60631), com o objetivo de estimular a salivação. As pacientes depositaram a saliva em coletor estéril até completar aproximadamente $10 \mathrm{ml}$.

Os materiais coletados foram identificados e armazenados em temperatura de $-20^{\circ} \mathrm{C}$ e transferidos ao Laboratório de Patologia Molecular da F.O.U.S.P. para processamento. 


\subsection{Processamento laboratorial das amostras}

\subsubsection{Extração do DNA}

Foram extraídas 42 amostras de cone (16 de GC e 26 de GNC) e 52 de saliva (14 de GC e 38 de GNC).

O protocolo para este método de extração de DNA foi realizado através do Kit Forensic da Invitrogen ${ }^{\circledR}$ de acordo com as instruções do fabricante.

\subsubsection{Quantificação do DNA}

Foi realizada a quantificação em espectrofotômetro Beckman DU ${ }^{\circledR} 640$ com leitura em 260/280 nm utilizando uma alíquota de solução de cada amostra de DNA. A absorvência de $260 \mathrm{~nm}$ equivale à quantidade de DNA e a de $280 \mathrm{~nm}$ à de proteínas.

A pureza dos extraídos de DNA foi obtida pela razão de absorvência $260 / 280 \mathrm{~nm}$. O valor considerado ideal foi de 1,8 a 2,0. 


\subsubsection{Detecção bacteriana por PCR}

As amostras de DNA foram amplificadas pela técnica da PCR utilizandose iniciadores específicos baseados na seqüência do gene 16S rDNA e foram sintetizados pela Invitrogen conforme Ashimoto ${ }^{48}$.

As amplificações foram realizadas em volume final de $25 \mu \mathrm{l}$ contendo $2,5 \mu l$ de $10 \times$ PCR buffer, $1,0 \mu \mathrm{l}$ of $\mathrm{MgCl}_{2}(50 \mathrm{mM}), 1,0 \mu \mathrm{l}$ de dNTP mix $(0.2$ $\mathrm{mM}), 1,0 \mu \mathrm{l}$ de cada iniciador específico $(0,4 \mathrm{M}), 0,25 \mu \mathrm{l}$ Taq Platinum DNA polymerase $(0,5 U)$, e $2 \mu \mathrm{l}$ de DNA das amostras. A reação de amplificação foi realizada em um termociclador (Perkin Elmer, Gene Amp PCR System 9700, Norwalk, CT, USA) ${ }^{\circledR}$ :programado para $94^{\circ} \mathrm{C}$ por 5 minutos, 30 ciclos de $94^{\circ} \mathrm{C}$ por $30 \mathrm{~s}$, temperatura de anelamento adequada para cada par de iniciadores por $30 \mathrm{~s} ; 72^{\circ} \mathrm{C}$ por $30 \mathrm{~s}$, e $72^{\circ} \mathrm{C}$ por 5 minutos para a extensão final do DNA.

O controle positivo foi o DNA de cultura pura da bactéria: Porphyromonas gingivalis ATCC 33277. O controle negativo foi composto por todos os reagentes presentes na reação e isento do DNA genômico.

O resultado da reação foi visualizado através da eletroforese do DNA amplificado (78 V / $40 \mathrm{~min}$ ) em gel de agarose $2 \%$ e utilizando-se uma cuba horizontal com tampão de corrida TAE (Tris-acetato) 1x, pH 8,1. Para a visualização e documentação do gel de amplificação do DNA foi utilizado um transluminador de luz ultravioleta (Fotodyne,Inc). 


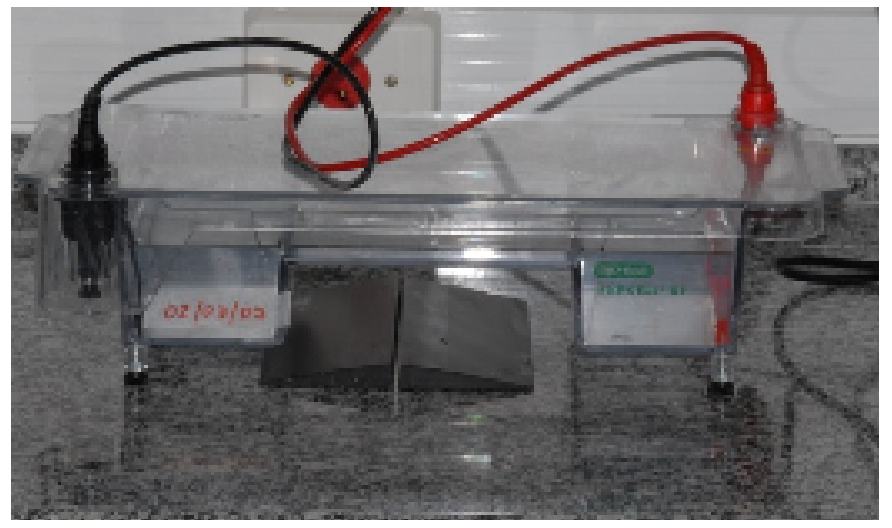

Figura 1 - Cuba de eletroforese

Em todos os géis foi colocado, juntamente com as amostras a serem analisadas, um marcador de "pares de base" (pb) (Low DNA Mass Ladder, Invitrogen), que representa uma mistura eqüimolar de fragmentos de DNA de 2000 a 1000 pb.

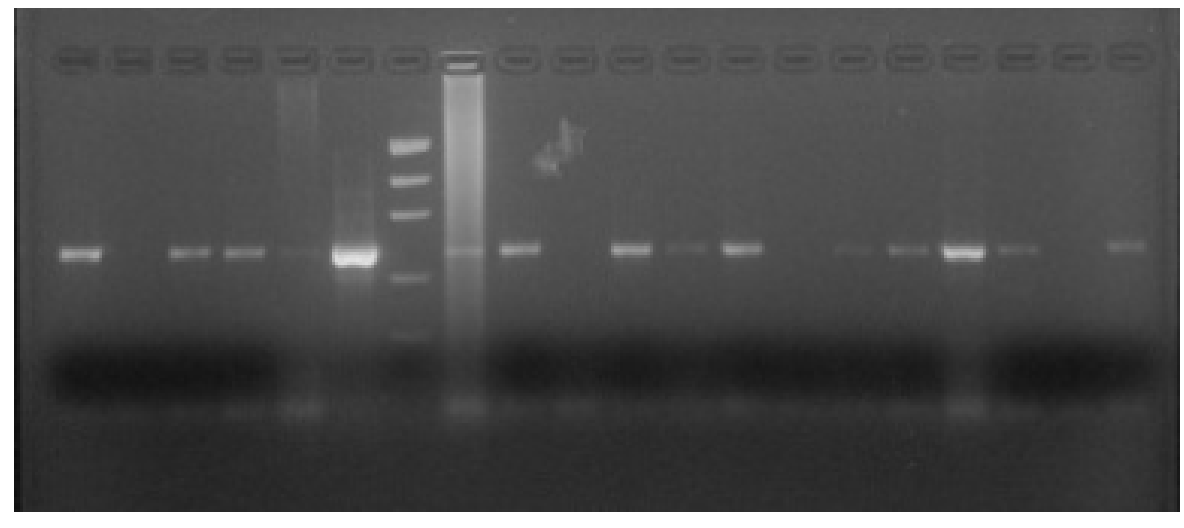

12 C- 1333718 C+L 9277955106812475882051109

Em verde - amostras amplificadas (presença de P.gingivalis) Em vermelho - amostras não amplificadas (ausência de P.gingivalis) Figura 2 - Visualização do DNA em gel de agarose 


\subsection{Análise Estatística}

Os dados, inicialmente, foram resumidos por estatísticas descritivas das freqüências absolutas e relativas (percentuais), medidas de tendência central (média e mediana) e de dispersão (mínimo, máximo e desvio padrão).

Testes de associação (Qui-Quadrado de Pearson e Exato de Fisher) e razão de chances (Odds Ratio) foram calculados para avaliar relação entre a presença da doença e as variáveis qualitativas.

A condição periodontal foi analisada empregando-se PCS, $\mathrm{NCl}$, LEC/MG, IS e IP. A Idade gestacional na ocasião do parto, comprimento e peso do recém nascido, estatura e peso materno também foram avaliados entre os grupos. A comparação entre doentes e não-doentes foi feita por teste não-paramétrico de Mann-Whitney.

Os grupos também foram comparados com relação à presença/ausência do microorganismo P. gingivalis por teste Qui-Quadrado de Pearson. A correlação entre as variáveis quantitativas foi observada e avaliada pelo coeficiente de correlação (c.c.) de Spearman. Adotou-se o nível de significância de 5\%, para rejeição da hipótese de nulidade. 
4 RESULTADOS 


\subsection{Análise da casuística}

A idade materna variou entre 18 e 35 anos (média de 27 anos $\pm 4,79$ ) no GC e entre 17 e 35 anos (média de $27 \pm 5,08$ ) no GNC, não havendo diferença estatisticamente significativa entre os grupos $(p<0,451)$.

A distribuição das pacientes do GC de acordo com o tipo de lesão valvar mostrou que $31(59,6 \%)$ casos apresentavam valvopatia mitral (Tabela 1)

Tabela 1 - Distribuição do tipo de lesão valvar cardíaca no grupo GC.

\begin{tabular}{crrrr}
\hline \multirow{2}{*}{ Tipo de lesão } & \multicolumn{3}{c}{ Lesão cardíaca valvar } & \multirow{2}{*}{ Total N } \\
\cline { 2 - 4 } & Mi \% (n) & Ao \% (n) & Mi-Ao \% (n) & \\
\hline Valva Natural & $71(22)$ & $50(1)$ & $94,7(18)$ & $78,8(41)$ \\
& & & & \\
Prótese Valvar & $29(9)$ & $50(1)$ & $5,3(1)$ & $21,2(11)$ \\
Total & $59,6(31)$ & $3,9(2)$ & $36,5(19)$ & $100(52)$ \\
\hline
\end{tabular}

$\mathrm{Mi}=$ mitral

Ao= aórtica

Mi-Ao= mitro-aórtica

$\mathrm{n}=$ número de pacientes

O estudo quanto a gestações anteriores mostrou que $53(43,40 \%)$ eram primigestas, freqüência não diferente entre os grupos (Tabela 2). 
Tabela 2 - Distribuição do número de gestações, partos e abortos nos grupos

\begin{tabular}{|c|c|c|c|c|c|c|c|c|c|}
\hline \multirow{3}{*}{ Ocorrências } & \multicolumn{2}{|c|}{ No. gestações } & & \multicolumn{2}{|c|}{ Paridade (partos) } & \multicolumn{4}{|c|}{ Abortos } \\
\hline & GC & GNC & & GC & GNC & & GC & GNC & \\
\hline & $n / \%$ & $n / \%$ & P Valor & $n / \%$ & $n / \%$ & p Valor & $n / \%$ & $\mathrm{n} / \%$ & p Valor \\
\hline \multirow[t]{2}{*}{0} & - & - & & 19 & 37 & & 49 & 52 & \\
\hline & _ & _ & & $36,50 \%$ & $52,90 \%$ & & $94,20 \%$ & $74,30 \%$ & \\
\hline \multirow[t]{2}{*}{1} & 20 & 33 & & 17 & 21 & & 2 & 15 & \\
\hline & $38,50 \%$ & $47,10 \%$ & & $32,70 \%$ & $30,00 \%$ & & $3,80 \%$ & $21,40 \%$ & \\
\hline \multirow[t]{2}{*}{2} & 23 & 24 & & 11 & 9 & & 1 & 3 & \\
\hline & $44,20 \%$ & $34,30 \%$ & & $21,20 \%$ & $12,90 \%$ & & $1,90 \%$ & $4,30 \%$ & \\
\hline \multirow[t]{2}{*}{3} & 5 & 7 & $0676^{\mathrm{F}}$ & 3 & 1 & $0.281^{\mathrm{F}}$ & - & - & $0.006^{\mathrm{F}}$ \\
\hline & $9,60 \%$ & $10,00 \%$ & $0,6 / 6$ & $5,80 \%$ & $1,40 \%$ & 0,281 & - & - & 0,006 \\
\hline \multirow[t]{2}{*}{4} & 2 & 3 & & 2 & 2 & & _- & _ & \\
\hline & $3,80 \%$ & $5,70 \%$ & & $3,80 \%$ & $2,90 \%$ & & - & - & \\
\hline \multirow[t]{2}{*}{5} & 1 & 3 & & - & - & & - & - & \\
\hline & $1,90 \%$ & $4,30 \%$ & & - & - & & - & - & \\
\hline \multirow[t]{2}{*}{6} & 1 & 0 & & - & - & & - & - & \\
\hline & $1,90 \%$ & $0,00 \%$ & & _ & _ & & _ & _ & \\
\hline \multirow{2}{*}{ Total } & 52 & 70 & & 52 & 70 & & 52 & 70 & \\
\hline & $100,00 \%$ & $100,00 \%$ & & $100,00 \%$ & $100,00 \%$ & & $100,00 \%$ & $100,00 \%$ & \\
\hline
\end{tabular}

$\mathrm{GC}=$ Gestante cardiopata

GNC = Gestante não-cardiopata

$\mathrm{n}=$ número de pacientes

$p=$ valor de $p$

$F=$ teste exato de Fischer

Quanto aos antecedentes obstétricos verificou-se que o grupo das GNC teve maior freqüência, de aborto espontâneo $(p=0,006)$, como ilustra a Figura 3. 
Número de Abortos

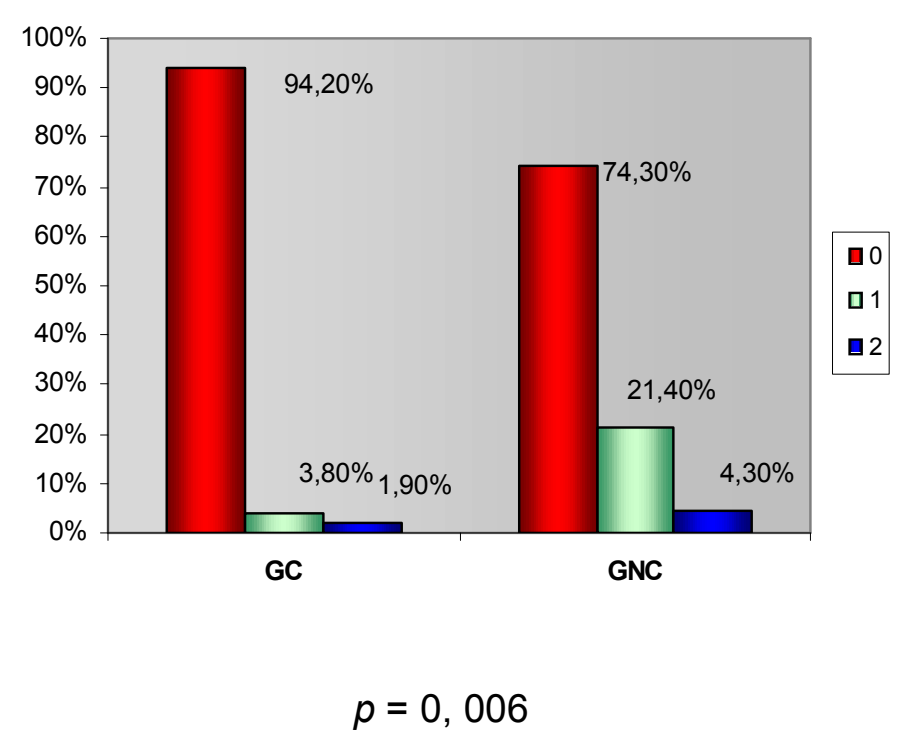

Figura 3 - Distribuição da amostra segundo os abortos espontâneos

A análise da distribuição dos tipos de medicamentos prescritos durante o estudo mostrou que o digital $(32,70 \%)$, a furosemida $(32,70 \%)$ e os beta-bloqueadores $(19,20 \%)$ foram os mais utilizados no grupo das GC (Tabela 3).

Todas as pacientes mantiveram a profilaxia secundária da doença reumática com penicilina $\mathrm{G}$ benzatina, de acordo com as recomendações da Sociedade de Cardiologia do Estado de São Paulo e da American Heart Association. 
Tabela 3 - Distribuição do tipo de medicamento prescrito durante o estudo nos dois grupos.

\begin{tabular}{cccc}
\hline Medicamento & GC & GNC & \\
\cline { 2 - 4 } & $\boldsymbol{\%}(\mathbf{n})$ & $\%(\mathbf{n})$ & $\boldsymbol{p}=$ valor \\
\hline Penicilina G Benzatina & $92,30 \%(48)$ & $0,0 \%(0)$ & $<0,0001^{\mathrm{P}}$ \\
Sulfato ferrroso & $73,10 \%(38)$ & $78,90 \%(56)$ & $0,454^{\mathrm{P}}$ \\
Ácido fólico & $65,40 \%(34)$ & $18,30 \%(13)$ & $<0,0001^{\mathrm{P}}$ \\
Polivitamínicos e poliminerais & $13,50 \%(7)$ & $8,50 \%(6)$ & $0,372^{\mathrm{P}}$ \\
Digitálicos & $32,70 \%(17)$ & $0,00 \%(0)$ & $<0,0001^{\mathrm{P}}$ \\
Anticoagulante oral & $9,60 \%(5)$ & $0,00 \%(0)$ & $0,012^{\mathrm{F}}$ \\
Beta- bloqueador & $19,20 \%(10)$ & $0,00 \%(0)$ & $<0,0001^{\mathrm{F}}$ \\
Hidroclorotiazida & $7,70 \%(4)$ & $1,40 \%(1)$ & $0,162^{\mathrm{F}}$ \\
Furosemida & $32,70 \%(17)$ & $1,40 \%(1)$ & $<0,0001^{\mathrm{P}}$ \\
Hidralazina & $5,80 \%(3)$ & $0,00 \%(0)$ & $0,073^{\mathrm{F}}$ \\
Cloreto de Potássio & $7,70 \%(4)$ & $0,00 \%(0)$ & $0,03^{\mathrm{F}}$ \\
Dipropionato de Benclometasona & $1,90 \%(1)$ & $0,00 \%(0)$ & $0,423^{\mathrm{r}}$ \\
\hline
\end{tabular}

GC: Gestante cardiopata

GNC: Gestante não-cardiopata

$\mathrm{n}$ : número de pacientes

$\mathrm{F}$ : teste Exato de Fisher

P: teste Qui-Quadrado de Pearson

$\%$ percentual

As medidas de comprimento e peso dos recém-nascidos e a idade gestacional quando do parto, expostas na Tabela 4, foram menores nas pacientes do grupo das GC quando comparadas às do GNC, como ilustra a Figura 4. 
Tabela 4 - Distribuição da amostra segundo a idade gestacional nos dias da consulta e do parto; comprimento e peso do bebê; estatura e peso maternos.

\begin{tabular}{|c|c|c|c|c|c|c|c|c|c|}
\hline \multirow[b]{2}{*}{ Variáveis } & \multicolumn{4}{|c|}{ GC } & \multicolumn{4}{|c|}{ GNC } & \multirow[b]{2}{*}{ p valor } \\
\hline & $\begin{array}{l}\text { Média } \\
\pm \mathrm{dp}\end{array}$ & Mediana & Mínimo & Máximo & $\begin{array}{l}\text { Média } \\
\pm d p\end{array}$ & Mediana & Mínimo & Máximo & \\
\hline \multirow{3}{*}{ IG coleta (semanas) } & 27,83 & & & & 28,01 & & & & \\
\hline & $( \pm 6,56)$ & 28,14 & 13,42 & 39,57 & $( \pm 7,69)$ & 29,43 & 13,00 & 39,71 & 0,824 \\
\hline & 38,54 & & & & 39,28 & & & & \\
\hline \multirow{3}{*}{$\begin{array}{l}\text { IG parto(semanas) } \\
\text { Comprimento ao } \\
\text { nascer }(\mathrm{cm})\end{array}$} & $( \pm 1,35)$ & 38,00 & 36,00 & 42,00 & $( \pm 1,79)$ & 39,00 & 32,00 & 42,00 & 0,0036 \\
\hline & 47,61 & & & & 48,95 & & & & \\
\hline & $( \pm 2,88)$ & 48,00 & 35,00 & 52,00 & $( \pm 2,72)$ & 49,00 & 38,00 & 53,00 & 0,0036 \\
\hline \multirow{2}{*}{ Peso do bebê $(\mathrm{g})$} & 3004,59 & & & & 3181,05 & & & & \\
\hline & $( \pm 641,86)$ & 3017,50 & 3000,00 & 4488,00 & $( \pm 784,36)$ & 3290,00 & 3000,00 & 4260,00 & 0,012 \\
\hline \multirow{2}{*}{ Estatura da mãe (m) } & 1,61 & & & & 1,59 & & & & \\
\hline & $( \pm 0,06)$ & 1,61 & 1,47 & 1,72 & $( \pm 0,07)$ & 1,59 & 1,40 & 1,82 & 0,126 \\
\hline \multirow{2}{*}{ Peso da mãe (kg) } & 65,40 & & & & 67,47 & & & & \\
\hline & & 65,50 & 46,00 & 90,00 & $( \pm 12,98)$ & 67,75 & 44,20 & 111,50 & 0,56 \\
\hline
\end{tabular}

$\mathrm{GC}=$ Gestante cardiopata

GNC = Gestante não-cardiopata

$\mathrm{dp}=$ desvio padrão

$\mathrm{cm}=$ centímetros

$\mathrm{g}=$ gramas

$\mathrm{m}=$ metro

$\mathrm{kg}=$ kilogramas

$p=$ valor de $p$ 

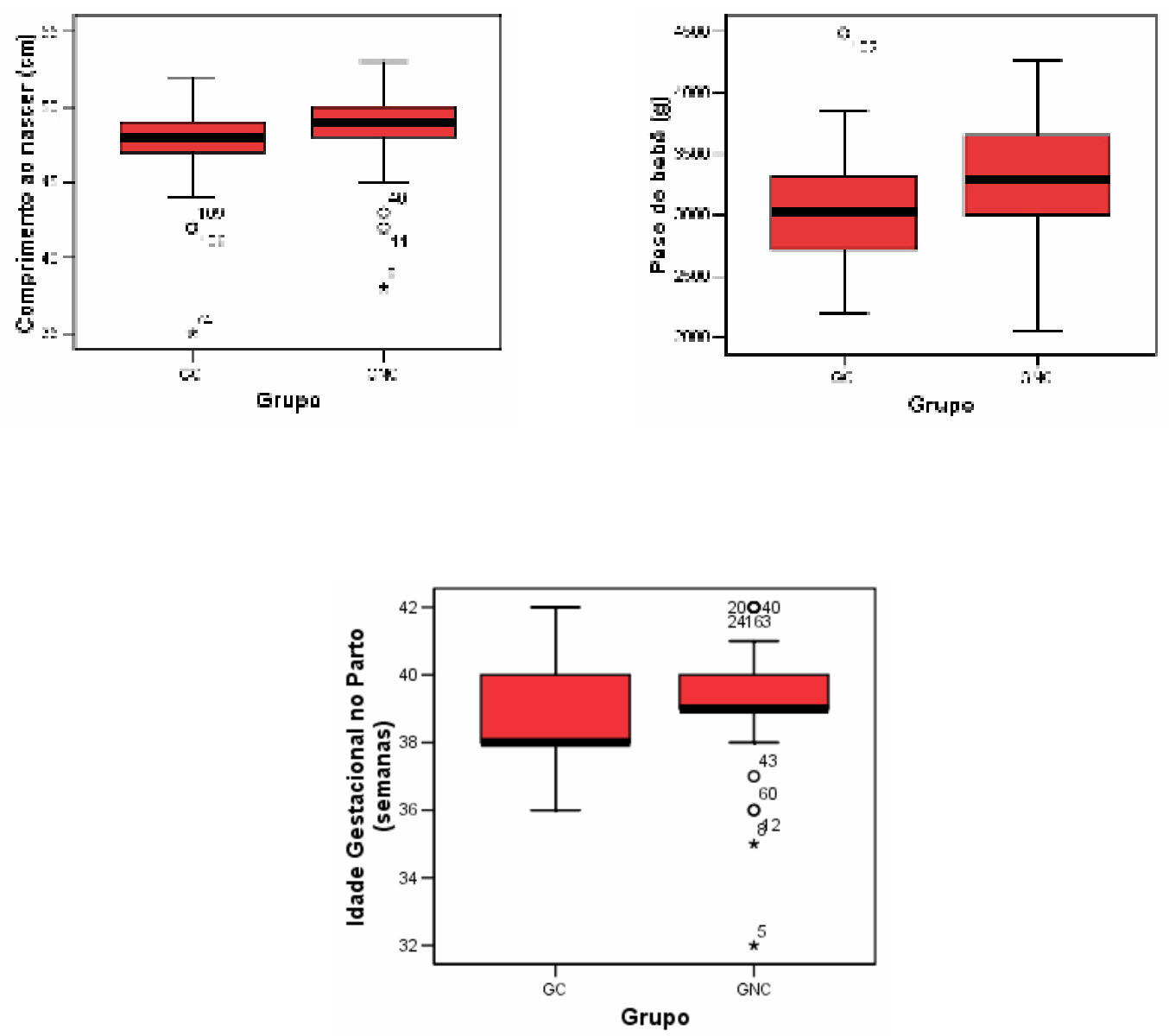

Figura 4 - Distribuição da amostra segundo a IG no dia parto, peso e comprimento do bebê ao nascer.

A análise das informações quanto aos hábitos de higiene bucal mostrou que as chances das gestantes do grupo GC usar fio dental são 2,3 vezes maior que às do grupo GNC. O contrário ocorre com o hábito de utilizar o enxaguatório bucal: 2,3 para as pacientes do GNC mais que as chances das integrantes do grupo GC (Tabela 5). 
Tabela 5 - Distribuição da amostra segundo uso diário de fio dental e enxaguatório bucal.

\begin{tabular}{ccccccc}
\hline & & GC & GNC & OR & IC $_{\mathrm{OR}}(\mathbf{9 5 \%})$ & $\boldsymbol{p}$-valor \\
\hline \multirow{2}{*}{ Uso fio dental } & $\mathbf{n}$ & 34 & 32 & 2,3 & $(1,10 ; 4,82)$ & $0,03^{\mathrm{P}}$ \\
& $\%$ & 65,40 & 45,70 & & & \\
Uso enxaguatório Bucal & $\mathbf{n}$ & 12 & 29 & 0,43 & $(0,20 ; 0,97)$ & $0,04^{\mathrm{P}}$ \\
& $\%$ & 23,10 & 41,40 & & & \\
\hline
\end{tabular}

$\mathrm{GC}=$ Gestante cardiopata

GNC = Gestante não-cardiopata

n: número de pacientes

OR $=$ Odds Ratio

$\mathrm{IC}_{\mathrm{OR}}=$ =́ndice de Correlação

$P=$ teste Qui- Quadrado de Pearson

$p=$ valor de $p$

\subsection{Resultados Clínicos}

Quanto aos parâmetros periodontais (Tabela 6), foi avaliado a PCS e se verificou nos grupos GC e GNC os valores mínimos de 0,94mm e $1,06 \mathrm{~mm}$ e máximos $2,67 \mathrm{~mm}$ e $3,73 \mathrm{~mm}$, respectivamente, com média de $1,52$ no GC e 1,45 no GNC ( $p=0,124)$; o mesmo ocorrendo com o NCl: 1,13 no GC e 1,06 no GNC ( $p=0,6119)$, assim como para o IS entre os grupos estudados: GC 7,34 e GNC 6,27 ( $p=0,502)$.

Quanto à LEC/MG não se observou diferença estatisticamente significativa das médias entre os grupos GC 0,41 e GNC 0,40 ( $p=0,3526)$. 
Com relação à variável IP, verificou-se média de 12,19 no GC e 13,48 no GNC ( $p=0,336)$, com valores máximos de $53,7 \%$ e $85 \%$, respectivamente. A média do número de dentes presentes foi 24,40 no GC e 24,71 no GNC.

Tabela 6 - Distribuição da amostra segundo as variáveis periodontais: profundidade clínica de sondagem (PCS), nível clínico de inserção $(\mathrm{NCl})$, linha esmalte-cemento / margem gengival (LEC/MG), índice de sangramento (IS), índice de placa (IP) e número de dentes

\begin{tabular}{|c|c|c|c|c|c|c|c|c|c|}
\hline \multirow{4}{*}{ Variáveis } & \multicolumn{4}{|c|}{ GC } & \multicolumn{4}{|c|}{ GNC } & \multirow{4}{*}{$p$} \\
\hline & \multicolumn{4}{|c|}{$n=52$} & \multicolumn{4}{|c|}{$n=70$} & \\
\hline & Média & & & & Média & & & & \\
\hline & $\pm d p$ & Mediana & Mínimo & Máximo & $\pm d p$ & Mediana & Mínimo & Máximo & \\
\hline \multirow{2}{*}{ PCS } & 1,52 & & & & 1,45 & & & & \\
\hline & $( \pm 0,37)$ & 1,46 & 0,94 & 2,67 & $( \pm 0,38)$ & 1,34 & 1,06 & 3,73 & 0,124 \\
\hline \multirow{2}{*}{$\mathrm{NCl}$} & 1,13 & & & & 1,06 & & & & \\
\hline & $( \pm 0,45)$ & 1,06 & 0,25 & 2,44 & $( \pm 0,36)$ & 1,04 & 0,12 & 2,1 & 0,612 \\
\hline \multirow{2}{*}{ LEC/MG } & 0,41 & & & & 0,40 & & & & \\
\hline & $( \pm 0,25)$ & 0,38 & $-0,13$ & 1,26 & $( \pm 0,36)$ & 0,32 & $-0,13$ & 2,34 & 0,352 \\
\hline \multirow{2}{*}{ IS } & 7,34 & & & & 6,27 & & & & \\
\hline & $( \pm 6,18)$ & 5,5 & 0,00 & 26,7 & $( \pm 5,07)$ & 5,25 & 0,00 & 26,7 & 0,502 \\
\hline \multirow{2}{*}{ IP } & 12,19 & & & & 13,48 & & & & \\
\hline & $( \pm 12,94)$ & 7,32 & 0,00 & 53,7 & $( \pm 13,85)$ & 11,21 & 0,00 & 85 & 0,336 \\
\hline \multirow{2}{*}{ Dentes } & 24,40 & & & & 24,71 & & & & \\
\hline & $( \pm 2,63)$ & 25 & 20 & 28 & $( \pm 2,56)$ & 25 & 20 & 28 & 0,5177 \\
\hline
\end{tabular}

$p=$ valor de $p$

$\mathrm{n}=$ número

$\mathrm{dp}=$ desvio padrão

Aplicado o teste de Spearman, verificou-se correlação significativa do $\mathrm{NCl}$ e as variáveis idade gestacional $(p=0,004)$, peso materno $(p=0.036)$, LEC/MG $(p<0,0001)$, PCS $(p<0,0001)$ e IS $(p<0,0001)$, (Tabela 7; Figura 5). 
Tabela 7 - Correlação entre as variáveis estudadas e o nível clínico de inserção ( $\mathrm{NCl}$ ) de acordo com o teste de Spearman.

\begin{tabular}{ccc}
\hline Variáveis & \multicolumn{2}{c}{ NCI } \\
\hline Idade materna & c.c. & $-0,005$ \\
& $\boldsymbol{p}$ & 0,96 \\
Valvoplastia & c.c. & $-0,543$ \\
& $\boldsymbol{p}$ & 0,266 \\
& c.c. & 0,149 \\
Diagnóstico de Febre Reumática & $\boldsymbol{p}$ & 0,308 \\
& c.c. & 0,076 \\
Endocardite Infecciosa Prévia & $\boldsymbol{p}$ & 0,404 \\
Tratamento Periodontal Prévio & c.c. & 0,176 \\
& $\boldsymbol{p}$ & 0,677 \\
Idade Gestacional & c.c. & 0,261 \\
& $\boldsymbol{p}$ & 0,004 \\
Idade Gestacional no parto & c.c. & 0,03 \\
& $\boldsymbol{p}$ & 0,764 \\
estatura da mãe (m) & c.c. & 0,054 \\
& $\boldsymbol{p}$ & 0,557 \\
peso da mãe $(\mathrm{Kg})$ & c.c. & 0,19 \\
& $\boldsymbol{p}$ & 0,036 \\
comprimento ao nascer $(\mathrm{cm})$ & c.c. & 0,06 \\
& $\boldsymbol{p}$ & 0,549 \\
peso do bebê $(\mathrm{g})$ & c.c. & 0,051 \\
& $\boldsymbol{p}$ & 0,611 \\
IS & c.c. & 0,427 \\
& $\boldsymbol{p}$ & $<0,0001$ \\
LEC/MG & c.c. & $-0,572$ \\
& $\boldsymbol{p}$ & $<0,0001$ \\
PCS & c.c. & 0,619 \\
& $\boldsymbol{p}$ & $<0,0001$ \\
IP & c.c. & 0,126 \\
& $\boldsymbol{p}$ & 0,165 \\
\hline & & \\
& &
\end{tabular}

$\mathrm{NCl}$ = nível clínico de inserção

c.c. = coeficiente de correlação

$p=$ valor de $p$

$\mathrm{m}=$ metro

$\mathrm{kg}=$ kilogramas

$\mathrm{cm}=$ centímetros

$\mathrm{g}=$ gramas

IS = Índice de Sangramento

LEC/MG = Linha Esmalte-Cemento à Margem Gengival

PCS $=$ Profundidade Clínica de Sondagem

IP = Índice de Placa

Verificando-se correlação positiva moderada do $\mathrm{NCl}$ com o índice de sangramento (IS), como mostra a Figura 5. 


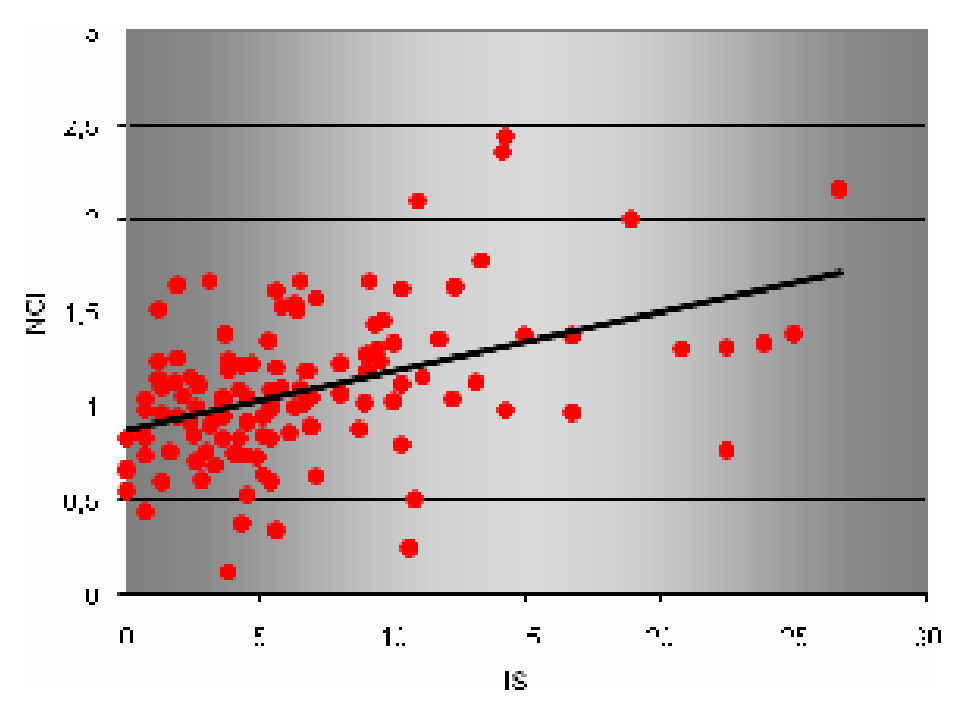

Figura 5 - Dispersão entre Nível Clínico de Inserção (NCl) e Índice de Sangramento (IS)

A presença da doença periodontal foi observada em 9,6\% (cinco) das pacientes do GC e em 15,7\% (11) das do GNC, proporções estas sem significação estatística (Tabela 8). 
Tabela 8 - Distribuição da amostra segundo a freqüência de doença periodontal

\begin{tabular}{ccccc}
\hline DP & & GC & GNC & p-Valor \\
\hline \multirow{2}{*}{ Sim } & $\mathbf{n}$ & 5 & 11 & \\
& $\%$ & $9,60 \%$ & $15,70 \%$ & $0,324^{P}$ \\
\multirow{4}{*}{ Não } & $\mathbf{n}$ & 47 & 59 & \\
& $\%$ & $90,40 \%$ & $84,30 \%$ & \\
\hline \multirow{2}{*}{ Total } & $\mathbf{n}$ & 52 & 70 & \\
& $\%$ & 100 & 100 & \\
\hline
\end{tabular}

DP = Doença Periodontal

$\mathrm{GC}=$ Gestante cardiopata

GNC = Gestante não- cardiopata

$p=$ valor de $p$

$\mathrm{n}=$ número de pacientes

$\%=$ percentual

$\mathrm{p}=$ teste Qui-Quadrado de Pearson

\subsection{Resultados microbiológicos}

O exame microbiológico identificou a $P$. gingivalis em maior número de amostras de saliva no GNC ( $p=0,007)$, (Tabela 9). 
Tabela 9 - Distribuição da amostra segundo presença de Porphyromonas gingivalis em sulco/bolsa e saliva

\begin{tabular}{cccccc}
\hline $\begin{array}{c}\text { Porphyromonas } \\
\text { gingivalis }\end{array}$ & GC & GNC & Total & p-valor \\
\hline Sulco/bolsa & $\mathbf{n}$ & 16 & 26 & 42 & 0,671 \\
Saliva & $\%$ & $33,30 \%$ & $37,10 \%$ & $35,60 \%$ & \\
& $\mathbf{n}$ & 14 & 38 & 52 & 0,007 \\
\hline \multirow{2}{*}{ Total da amostra } & $\mathbf{\%}$ & $29,20 \%$ & $54,30 \%$ & $44,10 \%$ & \\
& $\mathbf{n}$ & 48 & 70 & 118 & \\
\hline
\end{tabular}

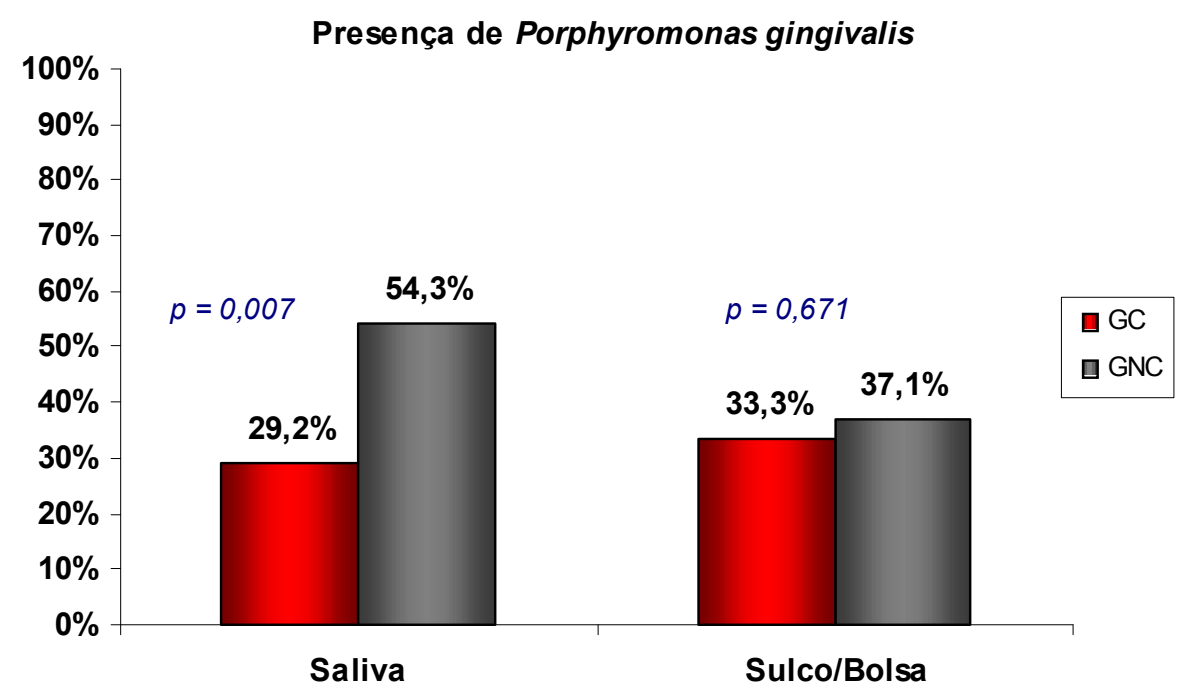

Figura - 6 - Presença de Porphyromonas gingivalis em amostras de saliva, sulco/ bolsa periodontal nos grupos 
5 DISCUSSÃO 


\section{Discussão}

O presente estudo provê os primeiros dados publicados descrevendo a condição periodontal como fator de risco durante a gravidez de mulheres portadoras de doença valvar reumática.

A ampla variação na incidência da doença periodontal, estimada entre $10 \%$ a $90 \%$, se deve à heterogeneidade da manifestação clínica da doença ${ }^{49-52}$. Esta variação é também influenciada pelo perfil da população e por fatores predisponentes como diabetes mellitus, hipertensão arterial, infecções sistêmicas e outras morbidades. Dentre os grupos que merecem atenção especial destaca-se o das portadoras de doença valvar reumática durante o período gravídico.

As crescentes alterações hemodinâmicas próprias da gestação interferem no débito cardíaco, na freqüência cardíaca e no volume sistólico $^{53}$. Tais modificações, ocorridas no curso da gestação normal, e a presença da DP durante a gravidez têm sido associadas ao aumento da morbidade materna, como a ocorrência de pré-eclampsia ${ }^{54-56}$ e de doença cardíaca isquêmica ${ }^{57-59}$, e na piora da evolução obstétrico-fetal (nascimento prematuro e baixo peso ao nascer ${ }^{60-62}$ ) podendo aumentar o risco materno das valvopatas grávidas.

Hull $^{28}$ e Holmstrup ${ }^{29}$ demonstraram que a cavidade bucal é a principal porta de entrada para agentes etiológicos da El, considerada uma infecção 
grave porque, apesar dos avanços em seu diagnóstico e tratamento, ainda está associada a altas taxas de morbidade e mortalidade. Nesse sentido, a condição periodontal tem forte implicação no desenvolvimento da El em pacientes suscetíveis, como as portadoras de doença valvar reumática, cardiopatia considerada a principal causa de morte materna no ciclo gravídico-puerperal $^{34-36,63}$, exigindo um cuidado multidisciplinar por parte do cardiologista, do obstetra e do cirurgião dentista.

No presente estudo a média de idade de 27 anos favoreceu a baixa incidência da DP (15\% no GNC e 9,6\% no GC), semelhante ao estudo de Miller et $a l^{64}$, que observaram que as formas mais graves da DP foram encontradas em $30 \%$ da população idosa, percentual inferior aos $14 \%$ da população adulta jovem.

No que diz respeito ao tipo de doença valvar, dentre as 52 gestantes cardiopatas encontramos maior prevalência de valvopatia mitral (59,6\%). Sendo a lesão reumática mitral predominante no sexo feminino, ela tem também maior incidência durante a gravidez, como sugerem os relatos de Andrade $^{63}(37,0 \%)$ e Ávila et al. $(55,7 \%)^{53}$.

Neste estudo a não admissão de tabagistas visou impedir a interferência do seu efeito na DP, do mesmo modo como foi considerado por Dietrich $^{65}$, Spiekerman ${ }^{66}$ e Hujoel, ${ }^{67}$ que justificaram a exclusão das pacientes tabagistas, pois o hábito de fumar poderia ser motivo de confusão para a condição clínica periodontal.

Quanto à paridade, o número de gestações foi semelhante nos grupos, o que homogeiniza a amostra, não permitindo que a paridade possa 
ter influência nos resultados, pois na primigesta aumenta o risco de complicações, como o risco de pré-eclampsia ${ }^{54,56}$.

Durante a gravidez recomenda-se evitar o uso de fármacos, pois a quase totalidade deles ultrapassa a barreira placentária e podem determinar alterações na embriogênese e no desenvolvimento fetal. Porém quando o tratamento medicamentoso é essencial à sobrevida materna a administração de fármacos se faz necessária, como ocorreu em percentual expressivo do GC, como mostra a Tabela 3.

No que diz respeito à prevenção, a administração contínua da penicilina $G$ benzatina ${ }^{37,68}$, a cada três semanas, foi mantida durante a gravidez para prevenção de novos surtos, particularmente em nosso país, onde a prevalência da doença e de infecção estreptocócica é alta ${ }^{69,70}$. Além disso, surtos reumáticos durante a gravidez aumentam o risco materno em decorrência da cardite, fetal, devido ao abortamento espontâneo ${ }^{71,72}$

Poderia se conjecturar que o uso preventivo da penicilina $G$ benzatina, tenha contribuído para menor freqüência de DP no grupo GC. Neste aspecto, estudos prévios demonstraram que antibióticos como Metronidazona, Tetraciclina, Clindamicina ${ }^{73-75}$ e Amoxicilina ${ }^{76}$, usados na terapêutica coadjuvante da periodontite, mostraram-se eficazes na cura da infecção intracelular por $P$. gingivalis ${ }^{73}$. Contudo, nenhum estudo considerou o uso da penicilina benzatina no tratamento da DP.

Desse modo, estes resultados não permitem excluir a possível interferência da penicilina, em uso profilático, na ocorrência ou evolução da 
DP. Contudo a sua menor incidência no grupo GC, merece reflexão sobre o real benefício da penicilina na prevenção da DP.

Tão importante quanto os estudos sobre a associação entre DP e doença cardíaca ${ }^{57-59}$, são os trabalhos que mostram a forte relação entre DP e gestação ${ }^{77,78}$. Salienta-se que o nível de evidência entre a associação DP e El é baixo e limitado a estudos de relatos de casos. A correspondência entre DP e gestação é salientada por Mascarenhas ${ }^{79}$, Ojanotko- Harri ${ }^{80}$ e Raber-Durlacher ${ }^{81}$ em trabalhos em que sugerem ser a gengivite uma manifestação oral freqüente na mulher grávida. $\mathrm{O}$ aumento da vascularização e a inflamação gengival têm sido reportados como resultado do incremento dos níveis de estrógeno e progesterona durante a gravidez ${ }^{82}$.

Os valores menores de comprimento, peso do bebê e da idade gestacional quando do parto, no grupo GC, estão de acordo com Avila $^{36}$, Andrade $^{63}$ e Faccioli $^{83}$, corroborando a evidência da participação da doença valvar reumática no comprometimento do crescimento fetal.

Segundo Jeffcoat ${ }^{61}$, Martin $^{62}$ e Agueda $^{60}$ a associação entre DP e NBP é causa de morbidade e mortalidade perinatal, tendo sido prematuras aproximadamente $12 \%$ das crianças. Entretanto, Offenbacher ${ }^{84,85}$, Jeffcoat ${ }^{61,}$ ${ }^{86}$, Madianos ${ }^{87}$, Lopez ${ }^{88}$, Lieff ${ }^{89}$ e Lunardelli ${ }^{90}$ observaram que mulheres com crianças de baixo peso têm saúde periodontal tão precária quanto aquelas com crianças nascidas de peso normal.

Neste estudo verificou-se que a doença valvar reumática foi o mais forte determinante para a condição dos recém-nascidos do que a DP, visto 
que o GNC, grupo que apresentou maior incidência de DP, teve bebês maiores em comparação com os do GC.

Segundo Russel ${ }^{91}$, durante a gestação as alterações bucais podem ocorrer como resultado das mudanças alimentares e da deficiência da higiene bucal, exacerbadas pelas modificações fisiológicas da gravidez. Associado a este aspecto, há falta de acesso ao tratamento odontológico e mitos que cercam a segurança com cuidados dentários durante a gestação, impedindo que mulheres grávidas tenham boa saúde oral. O presente estudo apontou que a chance das GC usar fio dental é 2,3 vezes às chances das GNC, sugerindo naquelas uma maior conscientização dos hábitos de higiene bucal por saberem dos riscos que a cardiopatia as expõe. Porém, quando analisados os parâmetros periodontais, observou-se que, com exceção do IP, todos os parâmetros avaliados (LEC/MG, IS, PCS, NCl) tiveram tendência a valores maiores no grupo GC, demonstrando que o processo inflamatório e a destruição periodontal foram diferentes, quando comparados com o GNC. Do mesmo modo que Machuca ${ }^{92}$ e Staffolani ${ }^{93}$ foi observada uma correlação positiva entre IS e NCl em ambos os grupos.

De acordo com Dierickx ${ }^{65}$ e Takeuchi $^{94}$ a $P$. gingivalis, um microorganismo anaeróbico, amelanogênico, não sacarolítico e Gramnegativo, tem sido considerada um patógeno causador da periodontite crônica. Isto tem sido foco de estudos devido a sua alta diversidade em espécimes e forte virulência na periodontite crônica. Considerando que a $P$. gingivalis é um periodontopatógeno, Yano-Higuchi ${ }^{23}$ e Wolff ${ }^{95}$ sugerem que sua detecção em sulco/bolsa periodontal, deveria ser usada como indicador 
clínico para doença periodontal. Deste modo, encontramos maior percentagem do microorganismo em amostras de saliva no GNC (29,20\% versus $54,30 \%$ ), divergindo de Yokoyama ${ }^{96}$ que observou número similar de bactérias nas amostras de saliva das gestantes do seu estudo. Entretanto, talvez isto reforce a condição anteriormente descrita, em que as pacientes cardiopatas possuíam maior preocupação com a condição bucal, logo, menor quantidade de bactérias nas amostras.

O presente estudo permite perceber a importância da atenção odontológica quanto à prevalência e diagnóstico da doença periodontal na gestante portadora de doença valvar reumática, porque saúde oral é parte integrante da saúde geral, e a redução ou eliminação da inflamação e da infecção durante a gravidez diminuirão os riscos maternos e fetais. 


\subsection{Considerações Finais}

$\checkmark$ Não se verificou diferença entre gestantes cardiopatas e nãocardiopatas para os parâmetros clínicos periodontais: profundidade clínica de sondagem, nível clínico de inserção, linha esmaltecemento/margem gengival, índice de sangramento e índice de placa bacteriana.

$\checkmark$ A ocorrência do microorganismo Porphyromonas gingivalis nas amostras de sulco/bolsa periodontal foi semelhante entre gestantes portadoras ou não de cardiopatia valvar.

$\checkmark$ A ocorrência do microrganismo Porphyromonas gingivalis nas amostras de saliva das gestantes não-cardiopatas foi significativamente maior quando comparados os dois grupos.

\subsection{Limitações do estudo}

Apesar da $P$. gingivalis ser fortemente associada à presença de doença periodontal, o estudo microbiológico de outros microorganismos corroboraria os achados deste estudo. 
6 CONCLUSÕES 


\section{Conclusões}

O estudo comparativo entre gestantes portadoras de doença valvar reumática e de não-cardiopatas demonstrou que:

1. Não houve diferença entre os grupos quanto à condição clínica periodontal

2. A freqüência de Porphyromonas gingivalis em amostra de saliva foi significativamente maior no grupo de gestantes não-cardiopatas, porém não houve diferença nas amostras de sulco/bolsa periodontal. 
7 ANEXOS

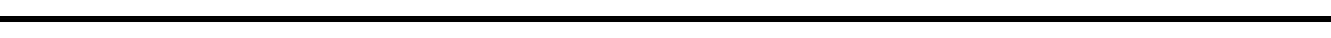




\section{ANAMTNESE}

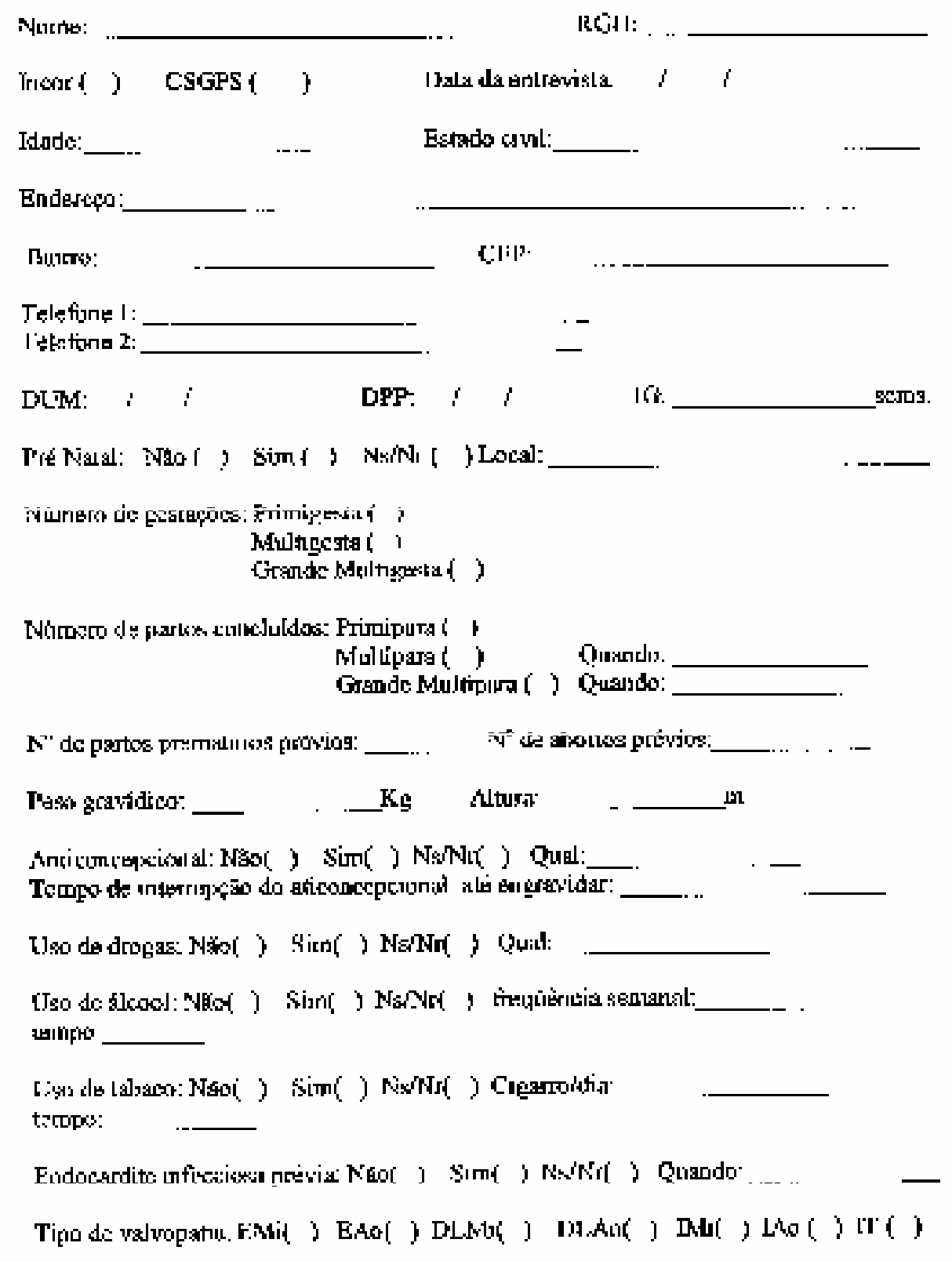


Prótese biológica: Não( ) $\operatorname{Sim}($ ) $\mathrm{Ns} / \mathrm{Nr}($ )

Prótese mecânica: Não( ) $\operatorname{Sim}($ ) $\mathrm{Ns} / \mathrm{Nr}($ )

CoMi: Não( ) $\operatorname{Sim}($ ) Ns/Nr( ) Quando:

VAlvoplastia catéter balão: Não( ) $\operatorname{Sim}($ ) $\mathrm{Ns/Nr(} \mathrm{)} \mathrm{Quando:}$

Profilaxia Doença Reumática: Não( ) Sim( ) Ns/Nr( )

Desde quando:

Alergia a medicamento: Não( ) $\operatorname{Sim}($ ) Ns/Nr( ) Qual:

Medicamentos cardiológico em uso: Atenolol __ mg/__dia ( )

Digoxina 0,25mg/__dia ( ) Propranolol __ mg/__ dia ( )

KCL_ $\mathrm{mg} /$ dia ( ) AAS inf. $100 \overline{\mathrm{mg} / \mathrm{dia}}(\overline{)}$

Medicamentos obstétricos em uso:Sulfato Ferroso $200 \mathrm{mg} / 2 x d i a($ )

Acido Fólico 5mg/dia ( )

Diabetes melitus: Não( ) $\operatorname{Sim}(\quad) \mathrm{Ns} / \mathrm{Nr}(\quad)$

Hipertensão: Não( ) $\operatorname{Sim}(） \operatorname{Ns/Nr(~)~}$

Infecções do trato genitourinário: $\mathrm{Não(} \mathrm{)} \operatorname{Sim}(\quad) \mathrm{Ns} / \mathrm{Nr}(\quad)$

Tratamento periodontal prévio: $\mathrm{Não(} \mathrm{)} \operatorname{Sim}($ ) Ns/Nr( ) Quando:

Tratamento periodontal atual: Não( ) $\operatorname{Sim}($ ) Ns/Nr( )

Freqüência diária de escovação: 1x/dia( ) 2x/dia( ) 3x/dia( ) 4x/diat( )

Freqüência diária uso fio dental:Não( ) $1 x /$ dia( ) $2 x /$ dia( ) 3x/dia( )4x/dia+( ) rara/( )

Enxagatório bucal: Não( ) $\operatorname{Sim}(） \mathrm{Ns} / \mathrm{Nr}($ ) freqüência:

Anamnese pós parto:

Sexo:

Idade gestacional:_____ sems Data nascimento:

Peso do bebê:

kg Altura: $\mathrm{cm}$

Hospital / Maternidade:

Tipo de parto: Normal ( ) Cesária ( )

Ápigar:

Intercorrência durante parto: Não( ) $\operatorname{Sim}(\quad) \mathrm{Ns} / \mathrm{Nr}($ ) Qual: 


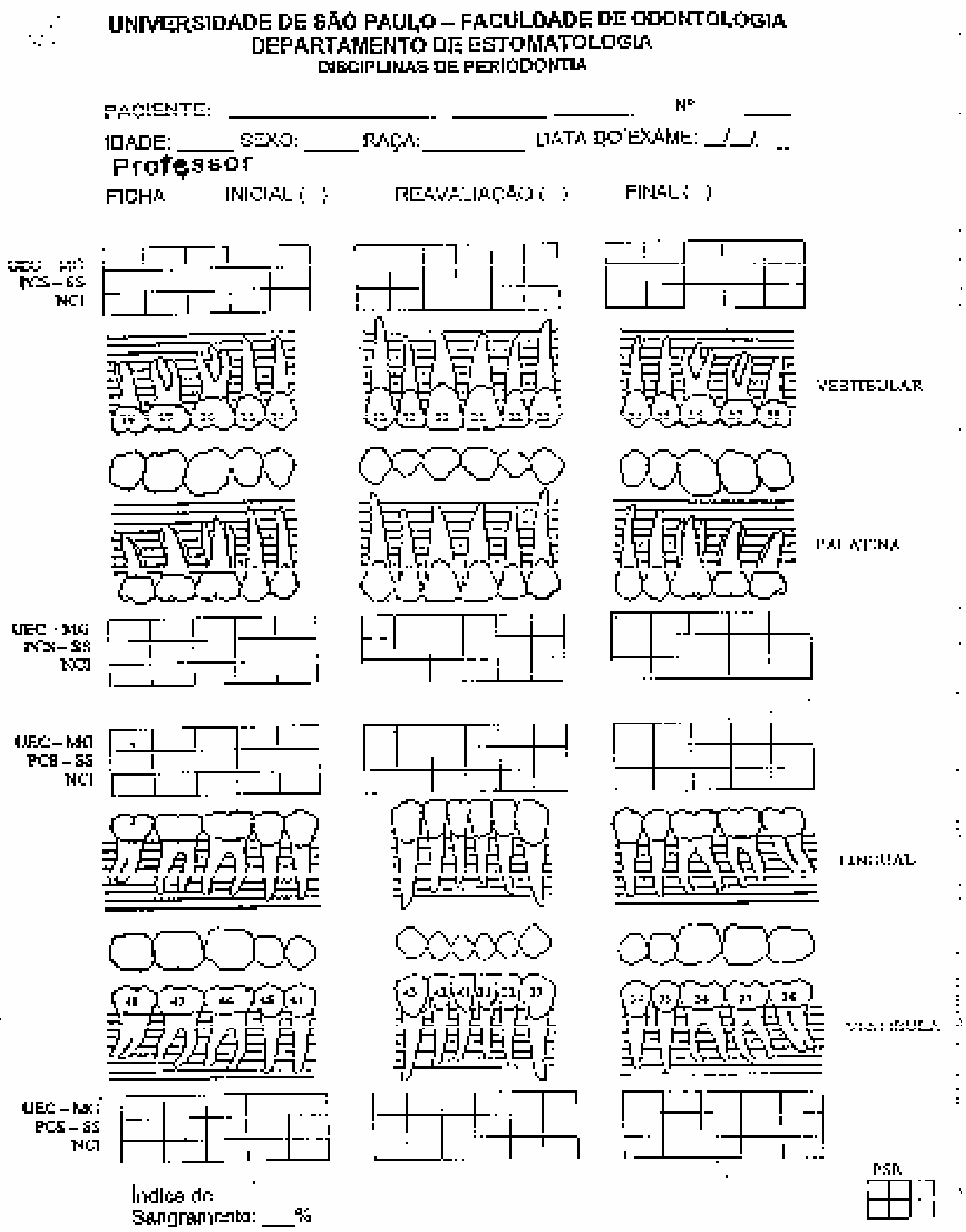


8 REFERÊNCIAS 


\section{Referências}

1. Syrjanen J, Peltola J, Valtonen V, livanainen M, Kaste M, Huttunen JK. Dental infections in association with cerebral infarction in young and middle-aged men. J Intern Med. 1989;225(3):179-84.

2. Mattila KJ, Nieminen MS, Valtonen VV, Rasi VP, Kesaniemi YA, Syrjala SL, Jungell PS, Isoluoma M, Hietaniemi K, Jokinen MJ. Association between dental health and acute myocardial infarction. Bmj. 1989;298(6676):779-81.

3. Kinane DF. Causation and pathogenesis of periodontal disease. Periodontol 2000. 2001;25:8-20.

4. Albandar JM, Brunelle JA, Kingman A. Destructive periodontal disease in adults 30 years of age and older in the United States, 1988-1994. Journal of periodontology. 1999;70(1):13-29.

5. Abegg C. [Oral hygiene habits among Brazilian adults in an urban area of southern Brazil]. Revista de Saúde Pública. 1997;31(6):58693. 
6. Gjermo P, Rosing CK, Susin C, Oppermann R. Periodontal diseases in Central and South America. Periodontol 2000. 2002;29:70-8.

7. Yalcin F, Eskinazi E, Soydinc M, Basegmez C, Issever H, Isik G, Berber L, Has R, Sabuncu H, Onan U. The effect of sociocultural status on periodontal conditions in pregnancy. Journal of periodontology. 2002;73(2):178-82.

8. Greene JC, Suomi JD. Epidemiology and public health aspects of caries and periodontal disease. J Dent Res. 1977;56 Spec No:C20-6.

9. Page RC. The pathobiology of periodontal diseases may effect systemic disease: of a paradigm. Ann Periodontol. 1998;3(1):108-20.

10. Kinane DF PM, Stathopoulou PG. Environment and other modifying factors of the periodontal disease. Periodontol 2000. 2006;40:107-19.

11. Last JM. Making the Dictionary of Epidemiology. Int J Epidemiol. 1996;25(5):1098-101.

12. Socransky SS, Haffajee AD. Evidence of bacterial etiology: a historical perspective. Periodontol 2000. 1994;5:7-25.

13. Listgarten M. Microbiological testing in the diagnosis of periodontal disease. Journal of periodontology. 1992;63(4 Suppl):332-7. 
14. Haber J, Kent RL. Cigarette smoking in a periodontal practice. Journal of periodontology. 1992;63(2):100-6.

15. Ah MK, Johnson GK, Kaldahl WB, Patil KD, Kalkwarf KL. The effect of smoking on the response to periodontal therapy. J Clin Periodontol. 1994;21(2):91-7.

16. Bergstrom J. Cigarette smoking as risk factor in chronic periodontal disease. Community Dent Oral Epidemiol. 1989;17(5):245-7.

17. Kinane DF, Chestnutt IG. Relationship of diabetes to periodontitis. Curr Opin Periodontol. 1997;4:29-34.

18. Loe H. Periodontal disease. The sixth complication of diabetes mellitus. Diabetes Care. 1993;16(1):329-34.

19. Amar S, Chung KM. Influence of hormonal variation on the periodontium in women. Periodontol 2000. 1994;6:79-87.

20. Zambon JJ. Periodontal diseases: microbial factors. Ann Periodontol. 1996;1(1):879-925.

21. Watson MR, Bretz WA, Loesche WJ. Presence of Treponema denticola and Porphyromonas gingivalis in children correlated with 
periodontal disease of their parents. J Dent Res. 1994;73(10):163640.

22. Sanz M, Lau L, Herrera D, Morillo JM, Silva A. Methods of detection of Actinobacillus actinomycetemcomitans, Porphyromonas gingivalis and Tannerella forsythensis in periodontal microbiology, with special emphasis on advanced molecular techniques: a review. J Clin Periodontol. 2004;31(12):1034-47.

23. Yano-Higuchi K, Takamatsu N, He T, Umeda M, Ishikawa I. Prevalence of Bacteroides forsythus, Porphyromonas gingivalis and Actinobacillus actinomycetemcomitans in subgingival microflora of Japanese patients with adult and rapidly progressive periodontitis. $\mathrm{J}$ Clin Periodontol. 2000;27(8):597-602.

24. Listgarten MA, Wong MY, Lai $\mathrm{CH}$. Detection of Actinobacillus actinomycetemcomitans, Porphyromonas gingivalis, and Bacteroides forsythus in an A. actinomycetemcomitans-positive patient population. Journal of periodontology. 1995;66(2):158-64.

25. Kamma JJ, Nakou M, Manti FA. Microbiota of rapidly progressive periodontitis lesions in association with clinical parameters. Journal of periodontology. 1994;65(11):1073-8. 
26. Scannapieco FA, Bush RB, Paju S. Periodontal disease as a risk factor for adverse pregnancy outcomes. A systematic review. Ann Periodontol. 2003;8(1):70-8.

27. Romero BC, Chiquito CS, Elejalde LE, Bernardoni CB. Relationship between periodontal disease in pregnant women and the nutritional condition of their newborns. Journal of periodontology. 2002;73(10):1177-83.

28. Hull MW, Chow AW. An Approach to Oral Infections and Their Management. Curr Infect Dis Rep. 2005;7(1):17-27.

29. Holmstrup P, Poulsen AH, Andersen L, Skuldbol T, Fiehn NE. Oral infections and systemic diseases. Dent Clin North Am. $2003 ; 47(3): 575-98$.

30. Li X, Kolltveit KM, Tronstad L, Olsen I. Systemic diseases caused by oral infection. Clin Microbiol Rev. 2000;13(4):547-58.

31. Essop MR, Nkomo VT. Rheumatic and nonrheumatic valvular heart disease: epidemiology, management, and prevention in Africa. Circulation. 2005;112(23):3584-91. 
32. Grinberg M, Avila WS. Endocardite infecciosa na gravidez In: Andrade J, Avila WS, editors. Doença cardiovascular, gravidez e planejamento familiar. São Paulo: Atheneu; 2003. p. 197-200.

33. Johnston W. D. EU. Infective endocarditis in pregnancy. In: Elkayam U GN, editor. Cardiac problems in pregnancy. New York: Alan R. Liss; 1982. p. 131-39.

34. Silversides CK, Colman JM, Sermer M, Siu SC. Cardiac risk in pregnant women with rheumatic mitral stenosis. Am J Cardiol. 2003;91(11):1382-5.

35. Hameed A, Karaalp IS, Tummala PP, Wani OR, Canetti M, Akhter MW, Goodwin I, Zapadinsky N, Elkayam U. The effect of valvular heart disease on maternal and fetal outcome of pregnancy. J Am Coll Cardiol. 2001;37(3):893-9.

36. Avila WS, Grinberg M, Decourt LV, Bellotti G, Pileggi F. [Clinical course of women with mitral valve stenosis during pregnancy and puerperium]. Arq Bras Cardiol. 1992;58(5):359-64.

37. Tarasoutchi F SG. Profilaxia da febre reumática. Rev Soc Cardiol Estado de São Paulo. 2005;15(1):85-91. 
38. Dajani A, Taubert K, Ferrieri P, Peter G, Shulman S. Treatment of acute streptococcal pharyngitis and prevention of rheumatic fever: a statement for health professionals. Committee on Rheumatic Fever, Endocarditis, and Kawasaki Disease of the Council on Cardiovascular Disease in the Young, the American Heart Association. Pediatrics. 1995;96(4 Pt 1):758-64.

39. Fisher JD. New York Heart Association Classification. Arch Intern Med. 1972;129(5):836.

40. Kubo SH, Schulman S, Starling RC, Jessup M, Wentworth D, Burkhoff D. Development and validation of a patient questionnaire to determine New York Heart Association classification. J Card Fail. $2004 ; 10(3): 228-35$.

41. Bennett JA, Riegel B, Bittner V, Nichols J. Validity and reliability of the NYHA classes for measuring research outcomes in patients with cardiac disease. Heart Lung. 2002;31(4):262-70.

42. Tonetti MS, Claffey N. Advances in the progression of periodontitis and proposal of definitions of a periodontitis case and disease progression for use in risk factor research. Group C consensus report of the 5th European Workshop in Periodontology. J Clin Periodontol. 2005;32 Suppl 6:210-3. 
43. Pinto V. Identificação de problemas. In: Pinto, VS. Saúde Bucal Coletiva. São Paulo: Santos; 2000.

44. O'Leary JL, O'Leary JA. Rudimentary Horn Pregnancy. Obstet Gynecol. 1963;22:371-5.

45. Loe H, Silness J. Periodontal Disease in Pregnancy. I. Prevalence and Severity. Acta Odontol Scand. 1963;21:533-51.

46. Romito GA, Pustiglioni FE, Saraiva L, Pustiglioni AN, Lotufo RF, Stolf NA. Relationship of subgingival and salivary microbiota to gingival overgrowth in heart transplant patients following cyclosporin A therapy. Journal of periodontology. 2004;75(7):918-24.

47. Hartroth B, Seyfahrt I, Conrads G. Sampling of periodontal pathogens by paper points: evaluation of basic parameters. Oral Microbiol Immunol. 1999;14(5):326-30.

48. Ashimoto A, Chen C, Bakker I, Slots J. Polymerase chain reaction detection of 8 putative periodontal pathogens in subgingival plaque of gingivitis and advanced periodontitis lesions. Oral Microbiol Immunol. 1996;11(4):266-73. 
49. El-Qaderi SS, Quteish Ta'ani D. Assessment of periodontal knowledge and periodontal status of an adult population in Jordan. Int J Dent Hyg. 2004;2(3):132-6.

50. Feldens EG, Kramer PF, Feldens CA, Ferreira SH. Distribution of plaque and gingivitis and associated factors in 3- to 5-year-old Brazilian children. J Dent Child (Chic). 2006;73(1):4-10.

51. Mumghamba EG, Manji KP, Michael J. Oral hygiene practices, periodontal conditions, dentition status and self-reported bad mouth breath among young mothers, Tanzania. Int $\mathrm{J}$ Dent Hyg. 2006;4(4):166-73.

52. Murray PE, Ede-Nichols D, Garcia-Godoy F. Oral health in Florida nursing homes. Int J Dent Hyg. 2006;4(4):198-203.

53. Avila WS, Rossi EG, Ramires JA, Grinberg M, Bortolotto MR, Zugaib M, da Luz PL. Pregnancy in patients with heart disease: experience with 1,000 cases. Clin Cardiol. 2003;26(3):135-42.

54. Siqueira FM, Cota LO, Costa JE, Haddad JP, Lana AM, Costa FO. Maternal periodontitis as a potential risk variable for preeclampsia: a case-control study. Journal of periodontology. 2008;79(2):207-15. 
55. Conde-Agudelo A, Villar J, Lindheimer M. Maternal infection and risk of preeclampsia: systematic review and metaanalysis. Am J Obstet Gynecol. 2008;198(1):7-22.

56. Contreras A, Herrera JA, Soto JE, Arce RM, Jaramillo A, Botero JE. Periodontitis is associated with preeclampsia in pregnant women. Journal of periodontology. 2006;77(2):182-8.

57. Genco R, Offenbacher S, Beck J. Periodontal disease and cardiovascular disease: epidemiology and possible mechanisms. J Am Dent Assoc. 2002;133 Suppl:14S-22S.

58. Kinane DF, Lowe GD. How periodontal disease may contribute to cardiovascular disease. Periodontol 2000. 2000;23:121-6.

59. Beck J, Garcia R, Heiss G, Vokonas PS, Offenbacher S. Periodontal disease and cardiovascular disease. Journal of periodontology. 1996;67(10 Suppl):1123-37.

60. Agueda A, Ramon JM, Manau C, Guerrero A, Echeverria JJ. Periodontal disease as a risk factor for adverse pregnancy outcomes: a prospective cohort study. J Clin Periodontol. 2008;35(1):16-22.

61. Jeffcoat MK, Hauth JC, Geurs NC, Reddy MS, Cliver SP, Hodgkins PM, Goldenberg RL. Periodontal disease and preterm birth: results of 
a pilot intervention study. Journal of periodontology. 2003;74(8):12148.

62. Martin JA, Hamilton BE, Sutton PD, Ventura SJ, Menacker F, Kirmeyer S, Munson ML. Births: final data for 2005. Natl Vital Stat Rep. 2007;56(6):1-103.

63. Andrade J. A doença reumática no ciclo gravídico-puerperal. São Paulo. Tese (Doutorado) - Faculdade de Saúde Pública da Universidade de São Paulo. 1981.

64. Miller AJ BJ, Carlos JP, Brown LJ, Löe H. . Oral health of United Stades Adults. The national Survey of Oral Health in US Employed Adults and Seniors: 1985-1986. National Findngs NH publication. 1987:87- 2868 .

65. Dietrich T, Garcia RI. Associations between periodontal disease and systemic disease: evaluating the strength of the evidence. Journal of periodontology. 2005;76(11 Suppl):2175-84.

66. Spiekerman CF, Hujoel PP, DeRouen TA. Bias induced by selfreported smoking on periodontitis-systemic disease associations. J Dent Res. 2003;82(5):345-9. 
67. Hujoel PP, Drangsholt M, Spiekerman C, DeRouen TA. Periodontitissystemic disease associations in the presence of smoking--causal or coincidental? Periodontol 2000. 2002;30:51-60.

68. Dajani AS, Taubert KA, Wilson W, Bolger AF, Bayer A, Ferrieri P, Gewitz MH, Shulman ST, Nouri S, Newburger JW, Hutto C, Pallasch TJ, Gage TW, Levison ME, Peter G, Zuccaro G, Jr. Prevention of bacterial endocarditis. Recommendations by the American Heart Association. Jama. 1997;277(22):1794-801.

69. Lue HC, Wu MH, Wang JK, Wu FF, Wu YN. Three- versus four-week administration of benzathine penicillin G: effects on incidence of streptococcal infections and recurrences of rheumatic fever. Pediatrics. 1996;97(6 Pt 2):984-8.

70. Lue HC, Wu MH, Wang JK, Wu FF, Wu YN. Long-term outcome of patients with rheumatic fever receiving benzathine penicillin $G$ prophylaxis every three weeks versus every four weeks. J Pediatr. 1994;125(5 Pt 1):812-6.

71. Chesley LC. Severe rheumatic cardiac disease and pregnancy: the ultimate prognosis. Am J Obstet Gynecol. 1980;136(5):552-8.

72. Chesley LC. Rheumatic cardiac disease in pregnancy. Long-term followup. Obstet Gynecol. 1975;46(6):699-705. 
73. Eick S, Pfister W. Efficacy of antibiotics against periodontopathogenic bacteria within epithelial cells: an in vitro study. Journal of periodontology. 2004;75(10):1327-34.

74. Mishkin DJ. Re: Rationale for use of antibiotics in periodontics. Walker C, Karpinia K (2002;73:1188-1196). Journal of periodontology. 2003;74(4):566; author reply

75. Bollen CM, Quirynen M. Microbiological response to mechanical treatment in combination with adjunctive therapy. A review of the literature. Journal of periodontology. 1996;67(11):1143-58.

76. Liebana J, Castillo AM, Alvarez M. Periodontal diseases: microbiological considerations. Med Oral Patol Oral Cir Bucal. 2004;9 Suppl:82-91; 75-82.

77. Thomson WM, Broadbent JM, Poulton R, Beck JD. Changes in periodontal disease experience from 26 to 32 years of age in a birth cohort. Journal of periodontology. 2006;77( 6):947-54.

78. Moss KL, Beck JD, Offenbacher S. Clinical risk factors associated with incidence and progression of periodontal conditions in pregnant women. J Clin Periodontol. 2005;32(5):492-8. 
79. Mascarenhas P, Gapski R, Al-Shammari K, Wang HL. Influence of sex hormones on the periodontium. J Clin Periodontol. 2003;30(8):671-81.

80. Ojanotko-Harri AO, Harri MP, Hurttia HM, Sewon LA. Altered tissue metabolism of progesterone in pregnancy gingivitis and granuloma. $\mathrm{J}$ Clin Periodontol. 1991;18(4):262-6.

81. Raber-Durlacher JE, van Steenbergen TJ, Van der Velden U, de Graaff J, Abraham-Inpijn L. Experimental gingivitis during pregnancy and post-partum: clinical, endocrinological, and microbiological aspects. J Clin Periodontol. 1994;21(8):549-58.

82. Laine MA. Effect of pregnancy on periodontal and dental health. Acta Odontol Scand. 2002;60(5):257-64.

83. Faccioli R. Área valvar mitral estenótica em gestantes portadoras de doença reumática - correlação com o prognóstico perinatal. Tese (Doutorado) - Faculdade de Medicina da Universidade de São Paulo. 1989.

84. Offenbacher S, Lieff S, Boggess KA, Murtha AP, Madianos PN, Champagne CM, McKaig RG, Jared HL, Mauriello SM, Auten RL, Jr., Herbert WN, Beck JD. Maternal periodontitis and prematurity. Part I: Obstetric outcome of prematurity and growth restriction. Ann Periodontol. 2001;6(1):164-74. 
85. Offenbacher S, Katz V, Fertik G, Collins J, Boyd D, Maynor G, McKaig $\mathrm{R}$, Beck J. Periodontal infection as a possible risk factor for preterm low birth weight. Journal of periodontology. 1996;67(10 Suppl):110313.

86. Jeffcoat MK, Geurs NC, Reddy MS, Cliver SP, Goldenberg RL, Hauth JC. Periodontal infection and preterm birth: results of a prospective study. J Am Dent Assoc. 2001;132(7):875-80.

87. Madianos PN, Lieff S, Murtha AP, Boggess KA, Auten RL, Jr., Beck JD, Offenbacher S. Maternal periodontitis and prematurity. Part II: Maternal infection and fetal exposure. Ann Periodontol. 2001;6(1):17582.

88. Lopez NJ, Smith PC, Gutierrez J. Periodontal therapy may reduce the risk of preterm low birth weight in women with periodontal disease: a randomized controlled trial. Journal of periodontology. 2002;73(8):91124.

89. Lieff S, Boggess KA, Murtha AP, Jared H, Madianos PN, Moss K, Beck J, Offenbacher S. The oral conditions and pregnancy study: periodontal status of a cohort of pregnant women. Journal of periodontology. 2004;75(1):116-26. 
90. Lunardelli AN, Peres MA. Is there an association between periodontal disease, prematurity and low birth weight? A population-based study. J Clin Periodontol. 2005;32(9):938-46.

91. Russell SL, Mayberry LJ. Pregnancy and oral health: a review and recommendations to reduce gaps in practice and research. MCN Am J Matern Child Nurs. 2008;33(1):32-7.

92. Machuca G, Khoshfeiz O, Lacalle JR, Machuca C, Bullon P. The influence of general health and socio-cultural variables on the periodontal condition of pregnant women. Journal of periodontology. 1999;70(7):779-85.

93. Staffolani N, Guerra M, Pugliese M, Cardinale G, Gulino A. [Hormonal receptors in gingival inflammation]. Minerva Stomatol. 1989;38(8):8236.

94. Takeuchi Y, Umeda M, Sakamoto M, Benno Y, Huang Y, Ishikawa I. Treponema socranskii, Treponema denticola, and Porphyromonas gingivalis are associated with severity of periodontal tissue destruction. Journal of periodontology. 2001;72(10):1354-63.

95. Wolff L, Dahlen G, Aeppli D. Bacteria as risk markers for periodontitis. Journal of periodontology. 1994;65(5 Suppl):498-510. 
96. Yokoyama M, Hinode D, Yoshioka M, Fukui M, Tanabe S, Grenier D, Ito HO. Relationship between Campylobacter rectus and periodontal status during pregnancy. Oral Microbiol Immunol. 2008;23(1):55-9. 
APÊNDICE 


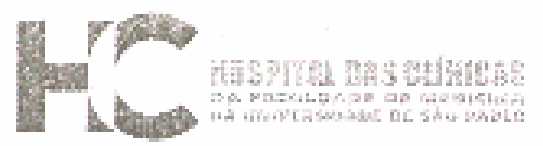

\section{APROV ILATOO}

A Comissöo de Ética para And́lise de Proj̣etos de Pesquiso - Cappesq do Diretoria Clínico do Hospital des Clínicrs e do Faculdade de Medicina da Universidada de Sha Paulo, en sessöo de 24.11.05, APROVOU o Protocalo de Pesquisa n 199/05, intitulada: "Avaliaçäo clínica e microblalógico periodantal em portaderos de cardiopatia valvar ma gestaçäo" apresentado pela cCMIssão CIENTIFICA E DE ÉTICA DO INSTITUTO DO CORAÇÃO, inclusive O Termo de Consentimento Livre e Esclorecido.

cabe on pesquisodor elaboror e apresertar a CAPPesẹ, os relatórios parciais e final sobre a pesquisa (Resoluçto do Conselho Nacional de Suúde no 196, de 10.10.1996, inciso IX. 2, letro "c")

Pesquisadar(a) Responsóvel: Profa. Dra. Walkiria Sampal Ayila Peaquisador (c) Exeoutonte: Dra. Lilia Tirnermah

CAPPesq, 24 de Novembro de 2005.

$$
\text { in }(x)
$$

PROF. DR. EUCLIDES AYRES DE CASTILHO

Pressidente da Comissö́o de Êtrica paro Anállse de Projetes de Pesquisa 
HOSPITAL DAS CLÍNICAS

Anexo D

DA

FACULDADE DE MEDICINA DA UNIVERSIDADE DE SÃO PAULO

TERMO DE CONSENTIMENTO LIVRE E ESCLARECIDO

(Instruções para preenchimento no verso)

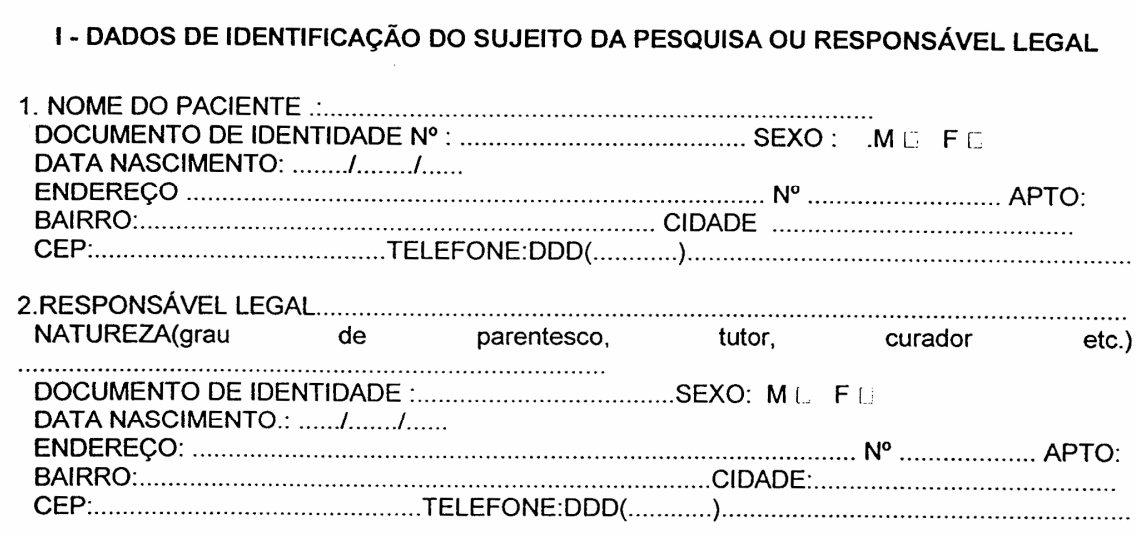

II - DADOS SOBRE A PESQUISA CIENTÍFICA

1. TíTULO DO PROTOCOLO DE PESQUISA Avaliação Clínica e Microbiológica Periodontal em Portadoras de Cardiopatia Valvar na Gestação

PESQUISADOR: Lilia Timerman

CARGO/FUNÇÃO: Cirurgiã Dentista I INSCRIÇÃO CONSELHO REGIONAL № 32154 UNIDADE DO HCFMUSP:

3. AVALIAÇÃO DO RISCO DA PESQUISA:

$\begin{array}{lll}\text { SEM RISCO I } & \text { RISCO MINIMOX } & \text { RISCO MÉDIO } \\ \text { RISCO BAIXOI } & \text { RISCO MAIOR! } & \end{array}$

(probabilidade de que o individuo sofra algum dano como consequência imediata ou tardia do estudo)

4.DURAÇÃO DA PESQUISA : 36 meses 


\section{III- REGISTRO DAS EXPLICAÇÕES DO PESQUISADOR AO PACIENTE OU SEU REPRESENTANTE LEGAL SOBRE A PESQUISA, CONSIGNANDO:}

1. justificativa e os objetivos da pesquisa; 2. procedimentos que serão utilizados e propósitos, incluindo a identificação dos procedimentos que são experimentais; 3 . desconfortos e riscos esperados; 4 . benefícios que poderão ser obtidos; 5 . procedimentos alternativos que possam ser vantajosos para o individuo.

1- Você esta sendo convidada a participar deste estudo por estar grávida e apresentar doença na válvula do coração e qualquer infecção na sua boca pode por em risco a gravidez e principalmente a válvula do coração; o objetivo desta pesquisa é examinar e avaliar a gengiva da gestante. Antes de decidir se será ou não voluntária para este estudo leia o Termo de Consentimento.

2- Caso você concorde em fazer parte deste estudo, responderá um questionário seguido do exame da sua gengiva. Através da sondagem periodontal,que é um procedimento de rotina,poderemos avaliar a condição atual da sua gengiva.

3- O exame provocará o minimo de desconforto (dependendo da sensibilidade de cada pessoa), sem provocar danos à saúde da gestante, nem do bebê.

4- Através deste exame, poderemos avaliar se a situação que sua gengiva se encontra, pode ter relação com seu problema cardiaco, bem como melhorar as condições bucais de outras gestantes.

5- Sua participação não é obrigatória. A não aceitação não interfere no acompanhamento médico. 


\section{IV - ESCLARECIMENTOS DADOS PELO PESQUISADOR SOBRE GARANTIAS DO SUJEITO DA PESQUISA:}

1. acesso, a qualquer tempo, às informações sobre procedimentos, riscos e benefícios relacionados à pesquisa, inclusive para dirimir eventuais dúvidas.

A qualquer momento você poderá solicitar informações sobre o andamento da pesquisa. Você poderá também conversar com o pesquisador e escalarecer qualquer dúvida a respeito da pesquisa.

2. liberdade de retirar seu consentimento a qualquer momento e de deixar de participar do estudo, sem que isto traga prejuizo à continuidade da assistência.

Você tem a liberdade de retirar seu consentimento a qualquer momento e de deixar de participar do estudo, sem que isto cause prejuizo ao seu atendimento médico.

3. salvaguarda da confidencialidade, sigilo e privacidade.

As informações sobre você são confidernciais e serão tratadas com sigilo e com privacidade. Somente serão fornecidas a outras pessoas autorizadas por você. As observações feitas, não serão identificadas como sendo suas.

4. disponibilidade de assistência no HCFMUSP, por eventuais danos à saúde, decorrentes da pesquisa.

Se houver quarquer problema resultante desta pesquis, você trá disponivel o atendimento médico e odontológico no Instituto do Coração do Hospital das Clínicas da Faculdade de Medicina da Universiade de São Paulo.

5. viabilidade de indenização por eventuais danos à saúde decorrentes da pesquisa.

Você não receberá nenhuma compensação financeira pela participação nesta pesquisa. 


\section{FACULDADE DE SAÚDE PÚBLICA UNIVERSIDADE DE SÃO PAULO}

\section{TERMO DE CONSENTIMENTO LIVRE E ESCLARECIDO}

\section{Prezada Senhora,}

Estamos avaliando a saúde bucal das grávidas deste serviço.

Primeiramente faremos algumas perguntas, depois examinaremos sua gengiva, o exame provocará o mínimo de desconforto, sem provocar danos a sua saúde, nem do bebê.

A sua identidade assim como a condição de sua boca não será revelada a ninguém; esta avaliaçăo será também utilizada para a elaboraçāo da monografia de doutourado sob a orientação de um professor da Universidade de São Paulo, e os resultados serão publicados mesmo que não sejam satisfatórios.

Sua participação não é obrigatória. A não aceitação não interfere no acompanhamento médico.

Através deste exame, poderemos avaliar a situação que sua gengiva se encontra, bem como melhorar as condiçōes bucais de outras gestantes.

Qualquer dúvida, entre em contato com Dra. Lilia Timerman, no telefone : $5085-4218$.

\begin{tabular}{c}
\hline Nome da Paciente \\
\hline Nome da Testemunha \\
Nome da Pesquisadora
\end{tabular}

Nome da Pesquisadora

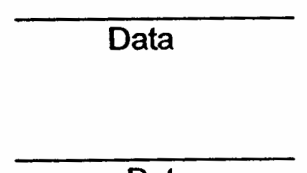

Data
Assinatura

Assinatura
Data
Assinatura 


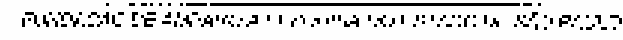

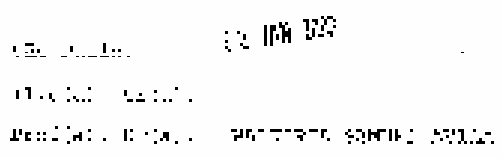

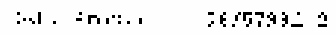

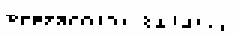

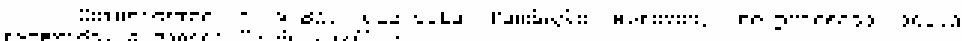

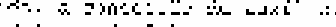

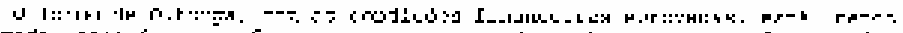

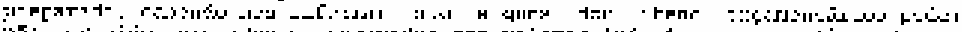

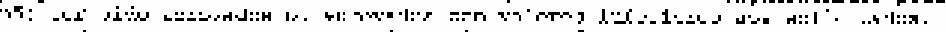

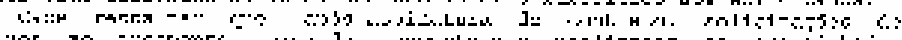

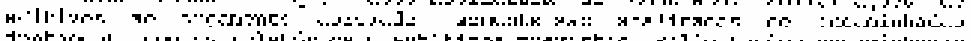

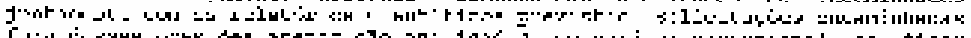

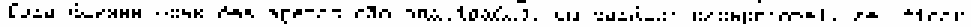
1. Hו:

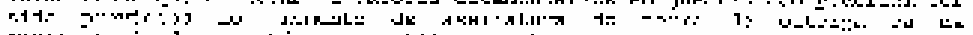

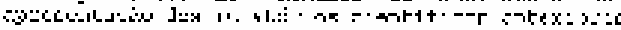

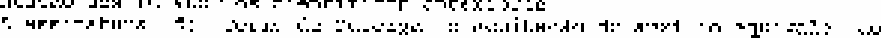

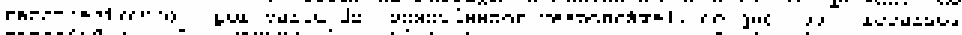

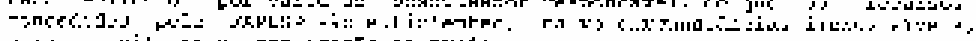

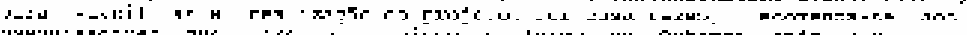
:

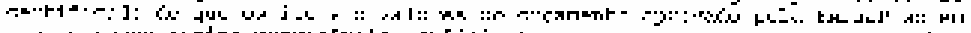

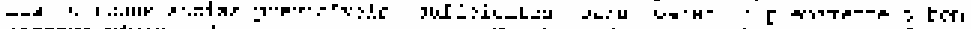

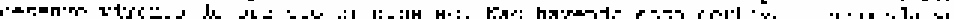

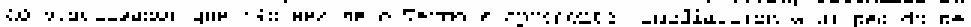

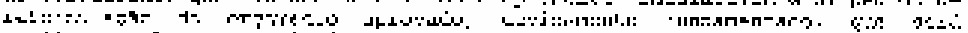

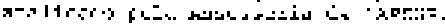

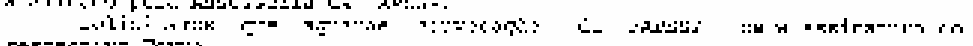
$=7+3$

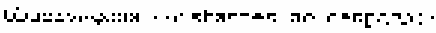

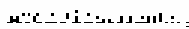

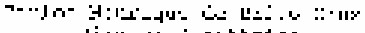
i i :

$-3 \cdot \cdots+\cdots+\cdots$

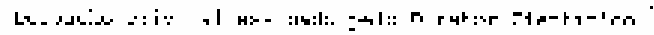

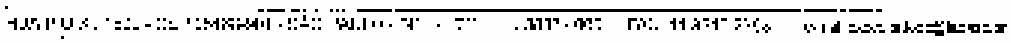


קit

Mam JOMHan:

'!r.r. : :r.

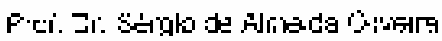

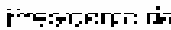

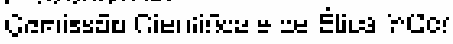

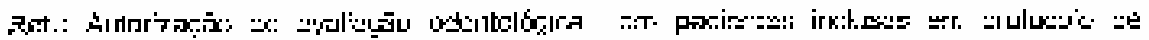

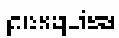

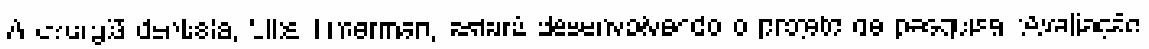

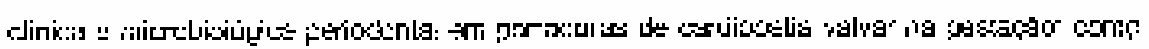
ت

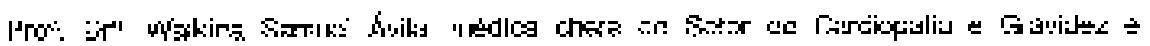

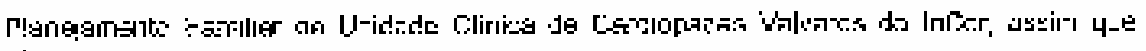

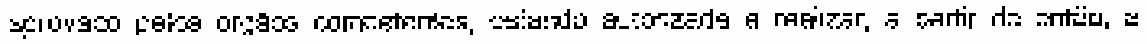

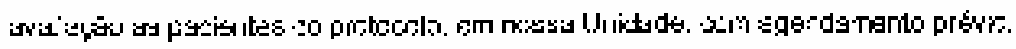

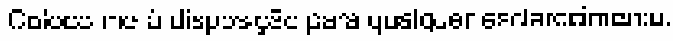

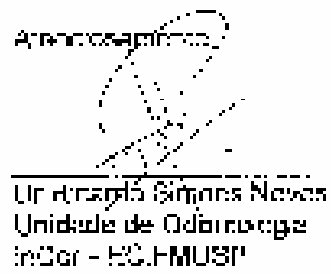

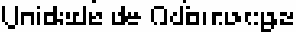

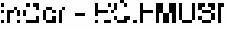



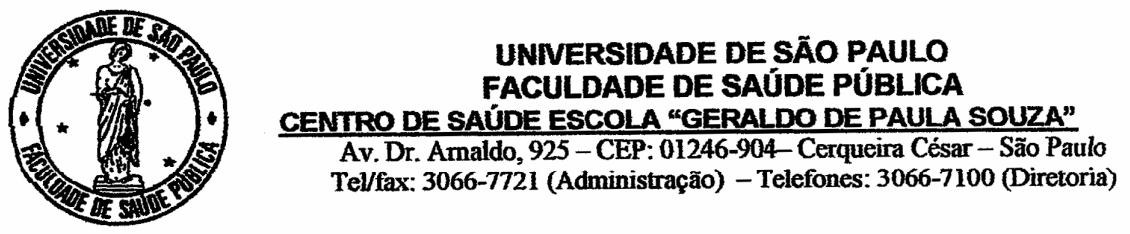

DECLARAÇÃo

Declaro para os devidos fins que LILIA TIMERMAN, está autorizada a realizar avaliação clínica e microbiológica periodontal nas gestantes matriculadas neste Centro de Saúde.

São Paulo, 15 de março de 2005.

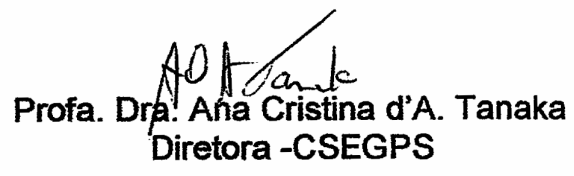

